Fecha de recepción: 26 de junio de 2020 Fecha de aceptación: 1 de agosto de 2020 Disponible en línea: 1 de septiembre 2020

Sugerencia de citación: Chaves-Castro, A. H. (2021). Análisis sobre la evolución del COVID-19 en Colombia: ¿se alcanzará el pico de contagio? tiempo\&economía, 8(1), 123-160. https://doi.org/10.21789/24222704.1672
Vol. 8 N. ${ }^{\circ} 1$

Enero - Junio del 2021

pp. $123-160$
HISTORIA ECONÓMICA, EMPRESARIAL Y DEL PENSAMIENTO

TIEMPO \& ECONOMÍA

DOI:

https://doi.org/10.21789/24222704.1672

\title{
Análisis sobre la evolución del COVID-19 en Colombia: ¿se alcanzará el pico de contagio?)
}

\author{
Analysis on the Evolution of COVID-19 \\ in Colombia: Will the Contagion Peak be \\ Reached?
}

\author{
Álvaro H. Chaves Castro \\ Profesor asociado, Escuela Colombiana de Ingeniería Julio \\ Garavito, Colombia \\ https://orcid.org/0000-0002-1865-3558 \\ alvaro.chaves@escuelaing.edu.co
}

\section{RESUMEN}

Se realiza un análisis de la evolución de los casos diarios de contagios y el número de muertes para Colombia y algunas ciudades con base en información oficial reportada por el Ministerio de Salud, con el fin de dar respuesta a la siguiente pregunta: ¿dada la trayectoria actual del nuevo coronavirus, es posible estimar el futuro pico de contagios? A partir de la construcción de una estructura de datos de panel, se estiman modelos con tendencia cuadrática temporal para el logaritmo del número de contagios y muertes por COVID-19. La estimación de la dinámica de los contagios y de las muertes de manera recursiva a partir del método de regresiones rolling window muestra un buen ajuste, permitiendo predecir cuándo se alcanzará 
el pico de la epidemia en función de los nuevos casos reportados oficialmente. Se estiman algunos factores asociados a la evolución de la pandemia, especialmente el efecto de la velocidad de contagio (tasa de reproducción efectiva, Ro) sobre la trayectoria futura de los contagios diarios. Además, se intenta estimar el impacto de las medidas de aislamiento preventivo adoptadas por las autoridades nacionales y regionales. Los resultados muestran que el pico de la pandemia en Colombia se alcanza aproximadamente a finales de agosto, período que coincide con estudios epidemiológicos más elaborados. El número promedio de nuevos casos diarios en el pico alcanzaría más de 10.000 contagios, mientras que el máximo número de fallecidos en el pico sería de 44.471. La estimación del impacto de las medidas de confinamiento muestra que se logra aplazar el pico y reducir el número de contagios y muertes.

Palabras clave: contagios, tendencia cuadrática, confinamiento, rolling window.

Códigos JEL: H12, H51, 110.

\section{ABSTRACT}

An analysis of the evolution of daily COVID-19 cases and number of deaths in Colombia and some Colombian cities is carried using official information reported by the Ministry of Health. This seeks to answer the following question: Considering the current trajectory of the new coronavirus, is it possible to estimate the future peak of infections? From the construction of a panel data structure, some models with a time quadratic trend are estimated for the number of infections and deaths logarithm. The estimation of such dynamics by the rolling window regression method shows a good fit, allowing to estimate the approximate date for the peak of the epidemic based on the new officially reported cases. Some factors associated with the progression of the pandemic are estimated, especially the effect of the speed of contagion (effective reproduction rate, Ro) on the future trajectory of daily infections. In addition, an attempt to estimate the impact of preventive social distancing measures adopted by national and regional authorities is performed. Results show that the peak of the pandemic in Colombia will be reached approximately at the end of August; finding that agrees with more elaborate epidemiological studies. The average number of new daily cases at the peak of the pandemic in Colombia would reach more than 10,000 , while the maximum number of deaths would be 44,471 . Estimates 
about the impact of confinement measures show that it is possible to delay the peak and reduce the number of infections and deaths.

Keywords: Contagion, quadratic trend, confinement, rolling window. JEL Codes: H12, H51, I10. 


\section{INTRODUCCIÓN}

Actualmente, el mundo está enfrentando una ola de incertidumbre y efectos negativos en todos los órdenes producto de la aparición de la pandemia de COVID-19, la cual se originó en la ciudad de Wuhan, China, el 10 de diciembre de 2019, donde el primer deceso se produjo un mes después, el 9 de enero de 2020. A partir de este momento, la velocidad de contagio de la enfermedad se reflejó en el número de casos reportados, que crecieron por todo el mundo de manera exponencial.

Colombia no fue la excepción. El primer caso de contagio en este país, clasificado como importado, se presentó en Bogotá el pasado 6 de marzo, involucrando a una mujer de 22 años procedente de la ciudad de Milán, Italia. Desde ese momento, el COVID-19 se ha ido expandiendo a lo largo del territorio nacional. Al 30 de julio del 2020, los datos oficiales reportados por el Ministerio de Salud indican que el número de casos confirmados en Colombia es del orden de 276.055, 9.454 muertes y 142.777 recuperados, dejando un saldo de 123.258 casos activos en el país. A nivel de ciudades, de acuerdo con la información del Instituto Nacional de Salud (INS), Bogotá lidera el número de casos con 95.199, seguida de Barranquilla (28.940), Cali (17.797), Cartagena (15.209), Leticia (2.372) y Villavicencio (2.160). ${ }^{1}$

La repuesta del Gobierno Nacional, en un intento por detener la expansión del virus, no se hizo esperar. El martes 24 de marzo se decretó una cuarentena en todo el país que terminaría el 25 de mayo. No obstante, dado el aumento en el número de casos y muertes, la medida se extendió hasta el 31 de julio de 2020. La idea de una cuarentena o medida de aislamiento preventivo es ganar tiempo y evitar el colapso en los sistemas de salud, así como tratar de aplazar el pico de contagio de una enfermedad.

En este documento se analiza la evolución diaria del COVID-19 para Colombia y las ciudades con el mayor número de contagios en este país, con el objetivo de encontrar alguna evidencia relacionada con la estimación del pico de contagios y las muertes asociadas al virus. Los resultados muestran que el pico de la pandemia en Colombia se alcanza aproximadamente a finales de agosto, período que coincide con estudios epidemiológicos más elaborados en Colombia. A partir de modelos con tendencia temporal cuadrática se extrapola el número de contagios y de muertes. Además, a partir de estimaciones recursivas tipo rolling window, se estima el momento en

\footnotetext{
Cifras oficiales reportadas diariamente por el Ministerio de Salud: http://www.ins.gov.co/Noticias/
} Paginas/Coronavirus.aspx. 
donde podría darse el pico de la curva de contagios y de muertes a nivel nacional, el cual está sujeto a un margen de incertidumbre enorme. Según dichas estimaciones, el número total de casos diarios que se alcanzarían en el pico está alrededor de 9.580 contagios, mientras que el número de fallecidos sería más de 10.000 personas. Ciudades como Bogotá, Cali y Barranquilla podrían alcanzar el pico de contagios y muertes diarias en un lapso de 7 semanas contadas a partir del 27 de mayo, para después transitar hacia un descenso lento. Las excepciones son Leticia y Villavicencio, donde aún es muy temprano estimar cuándo ocurrirá el pico de contagios y de muertes. Específicamente, para el número de muertes diarias, existen algunas ciudades en donde todavía no es posible determinar el momento exacto en el que ocurriría el pico.

En este trabajo - aún en etapa preliminar, y reconociendo cierto desconocimiento en cuanto a epidemiología - se parte de algunos elementos de los modelos más básicos, haciendo énfasis en el número de reproducción efectiva, cuyas estimaciones se toman de otros trabajos, con el fin de explicar la evolución en las tendencias de los casos diarios de contagios y de muertes. Así, la extrapolación de casos a partir de los modelos de tendencia cuadrática tiene en cuenta la influencia de este número, el cual podría determinar de manera adecuada la trayectoria futura del virus COVID-19.

El presente documento se estructura en seis secciones, de la cuales esta introducción es la primera. La segunda parte describe el número de reproducción efectiva $(R)$ a partir de un modelo estándar epidemiológico (SIR) con el fin de analizar la evolución futura de los casos diarios de contagios y muertes; al tiempo que analiza la evolución de los casos diarios de contagios y fallecidos por COVID-19. En la sección tercera se realiza una revisión del estado del arte, destacando los principales trabajos relacionados con la evolución del COVID-19 y los impactos económicos de la pandemia. La sección cuarta describe los modelos de tendencia cuadrática a fin de estimar la evolución en los casos de contagio y muertes. Así mismo, se describe la metodología utilizada y se presenta la estimación del momento en donde tiene lugar el pico (turning point) para los casos diarios de contagios y muertes. La quinta sección presenta los resultados de un ejercicio preliminar de estimación del impacto de las medidas de confinamiento sobre los nuevos casos diarios reportados de contagio y de muertes. La última sección presenta una serie de comentarios finales a manera de discusión. 


\section{NÚMERO DE REPRODUCCIÓN EFECTIVO Y DINÁMICA DEL CONTAGIO COVID-19}

Esta sección sigue de cerca la exposición realizada por Arroyo-Marioli et al. (2020) a partir del modelo básico original de Kermack y MacKendrick (1927). ${ }^{2}$ El modelo estándar describe la evolución diaria de los susceptibles $\left(S_{t}\right)$, infectados $\left(I_{t}\right)$ y recuperados $\left(R_{t}\right)(\mathrm{SIR})$ a partir de las ecuaciones 1,2 y 3 , las cuales se presentan en forma discreta:

$$
\begin{gathered}
S_{t}=S_{t-1}-\beta I_{t-1} \frac{S_{t-1}}{N} \\
I_{t}=I_{t-1}+\beta I_{t-1} \frac{S_{t-1}}{N}-\gamma I_{t-1} \quad \text { (Ec. 1) } \\
R_{t}=R_{t-1}+\gamma I_{t-1}
\end{gathered}
$$

En donde $N$ es el tamaño de la población, $\beta$ la tasa de crecimiento diaria del número de contagios de COVID-19 y $\gamma$ la tasa de transición diaria del estado de infectado a recuperado. El grupo de individuos recuperados está conformado por aquellos que no han muerto y se han recuperado completamente.

El número básico de reproducción $\left(R_{0}\right)$ se define como la relación entre la tasa de crecimiento de propagación de la enfermedad y la tasa diaria de transición (es decir, $R_{o} \equiv \beta / \gamma$ ), y muestra el número esperado de personas contagiadas por un individuo contagiado dentro de una población de individuos susceptibles de adquirir la enfermedad. Por su parte, el número de reproducción efectiva $\left(R_{t}\right)$ se define como $R_{t}=R_{o}{ }^{*}\left(S_{t-1} / N\right)$, y es igual al número esperado de individuos infectados por una persona infectada cuando una facción $\left(S_{t-1} / N\right)$ de individuos es susceptible. A partir de las ecuaciones 1,2 y 3 , la tasa de crecimiento diaria del número de individuos infectados es:

$$
\operatorname{gr}\left(I_{t}\right)=\frac{I_{t}}{I_{t-1}}-1=\gamma\left(R_{t}-1\right) \quad(\text { Ec. } 4)
$$

2 Veinte años después de la aparición de la peste bubónica que afectó a Mumbai en 1905-1906, Kermack y McKendrick intentaron responder la siguiente pregunta: ¿cómo se puede prevenir una pandemia? Para tal efecto, construyeron un modelo dinámico para ajustar los datos al modelo estadístico y encontraron que la evolución de una epidemia tiene la forma de una u invertida, que es lo que se conoce hoy en día como la curva epidemiológica. 
Si se denota la tasa de crecimiento estimada de individuos infectados por $(\mathrm{gr})^{\wedge}\left(I_{t}\right)$, asignando un valor para la tasa de transición $\gamma$, se puede reordenar la ecuación 4 para obtener finalmente la tasa de "reproducción efectiva", que mide la variación porcentual en el número de contagios en un período determinado:

$$
\begin{aligned}
& \frac{\widehat{g r}\left(I_{t}\right)}{\gamma}=R_{t}-1 \\
& \hat{R}_{t}=1+\frac{\widehat{g r}\left(I_{t}\right)}{\gamma}
\end{aligned}
$$

La tasa de reproducción efectiva que se muestra en la ecuación 5 se ha convertido en un concepto clave para prevenir la aparición de una pandemia (como la de COVID-19) e implementar medidas tendientes a aplanar la curva de contagios. ${ }^{3}$ Sin embargo, de acuerdo con el instituto alemán de virología Robert Koch, la tasa de reproducción efectiva $\left(\hat{R}_{t}\right)$ debe ser distinguida del número de reproducción básico (Ro) y del número de reproducción efectivo $\left(R_{t}\right)$. Mientras que $R_{t}$ (ver ecuación 3 ) indica cuántas personas se infectan, en promedio, después de tomar medidas de contención o una parte de la población es inmune, Ro describe cuántas personas son contagiadas por una persona infectada sin medidas de contención. De modo que $R_{o}$ asume que nadie ha sido vacunado, nadie tuvo la enfermedad y, por lo tanto, es inmune y no hay manera de frenar la propagación. De esta forma, cuando el número básico de reproducción $\left(R_{o}\right)$ es mayor que uno (1) quiere decir que la enfermedad se está propagando y el número de contagio está en aumento. De otro lado, cuando este es menor a 1, durante la propagación se infectan cada vez menos personas, en cuyo caso se podrá contener la propagación del virus.

De acuerdo con especialistas en epidemiología, parecería que la fase ascendente de la curva de contagios coincide con valores mayores a uno en el número básico de reproducción y que el número de contagios se incrementa con mayor rapidez. De igual forma, cuando se alcanza el pico y el número de contagios comienza a decrecer, el número de reproducción básico toma valores menores a 1 y es posible la contención del virus. Con el fin de ilustrar

3 Se trata simplemente de disminuir la propagación del virus con el fin de que el número de casos se distribuya a lo largo del tiempo, en vez de tener fuertes disparadas de la enfermedad y evitar el colapso de los sistemas de salud, al tiempo que se permite el aplazamiento del pico en la curva de contagios. 
este fenómeno, en la figura 1 se ha realizado una simulación de la distribución de una enfermedad (en este caso, COVID-19) de manera aleatoria a partir de una distribución gaussiana. ${ }^{4}$ Es importante resaltar que no se trata de una simulación realizada a partir de un modelo epidemiológico con ecuaciones diferencias tipo SIR, sino que simplemente se generan (de manera aleatoria) diferentes números usando una distribución gaussiana y se ajustan los datos a una curva no lineal, utilizando para ello el programa STATA 15.

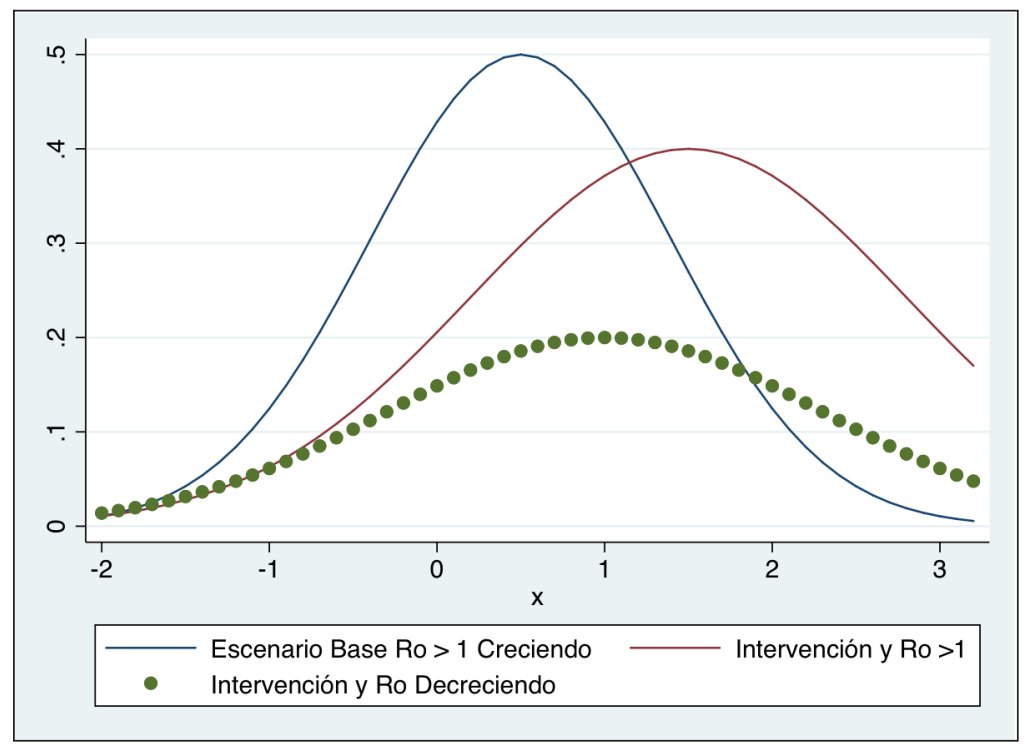

La curva azul punteada es un escenario en donde el número de casos crece de forma rápida en ausencia de algún tipo de intervención por parte del gobierno, es decir, sin la implementación de distanciamiento social o la implementación de métodos de testeo rápido para diagnosticar el virus. En el tramo izquierdo de la curva el número básico de reproducción sería mayor a 1 y el número de personas contagiadas iría en aumento hasta llegar al punto más alto de contagios (pico). Por su parte, la curva punteada de color naranja es la distribución del virus con intervención del gobierno y todavía con un valor de $R_{o}>1$, cuyo efecto sería aplazar el pico de contagio y aplanar la curva. La curva de color rojo sería el escenario ideal, es decir, aquel donde se ha logrado el aplanamiento de la curva con una estrategia de contención del virus encaminada a evitar el colapso del sistema de salud y los valores de $R_{o}$ menores a uno (1) se ubicarían en la parte derecha de la curva, lo que implica que el número de contagios sería decreciente en el tiempo. De
Figura 1.

Distribución Gaussiana del COVID-19 en Colombia
Fuente: elaboración propia con información del Ministerio de Salud de Colombia. Ajuste de la curva realizado a partir de simulación STATA 15.

4 La función presenta la siguiente forma $f(x)=\{1 / \sigma \sqrt{2 \pi}\} \exp \left[-(x-b)^{2} / 2 \sigma^{2}\right]$. 
acuerdo con la simulación, al parecer, Colombia está transitando aún en la curva naranja y el escenario ideal a alcanzar sería la curva roja.

Es importante resaltar que la dinámica que exhibe la distribución en la figura 1 depende del valor del número básico de reproducción de la enfermedad, que en Colombia actualmente es mayor a uno y se encuentra en el tramo ascendente de la distribución mostrada. En efecto, de acuerdo con estimaciones de Arroyo-Marioli et al. (2020), ${ }^{5}$ en Colombia, a comienzos de la pandemia este se encontraba alrededor de 2,6, presentando un descenso gradual hasta el 14 de abril de 2020 (1,32). A partir de esa fecha el número se ha mantenido más o menos constante. Sin embargo, el 5 de mayo incrementa a 1,48, período que coincide con un aumento significativo en el número de casos de COVID-19 en el país, tal como se puede apreciar en la figura 2, la cual incluye sus respectivos intervalos de confianza.

Figura 2.

Número de reproducción efectiva (R) e intervalos de confianza

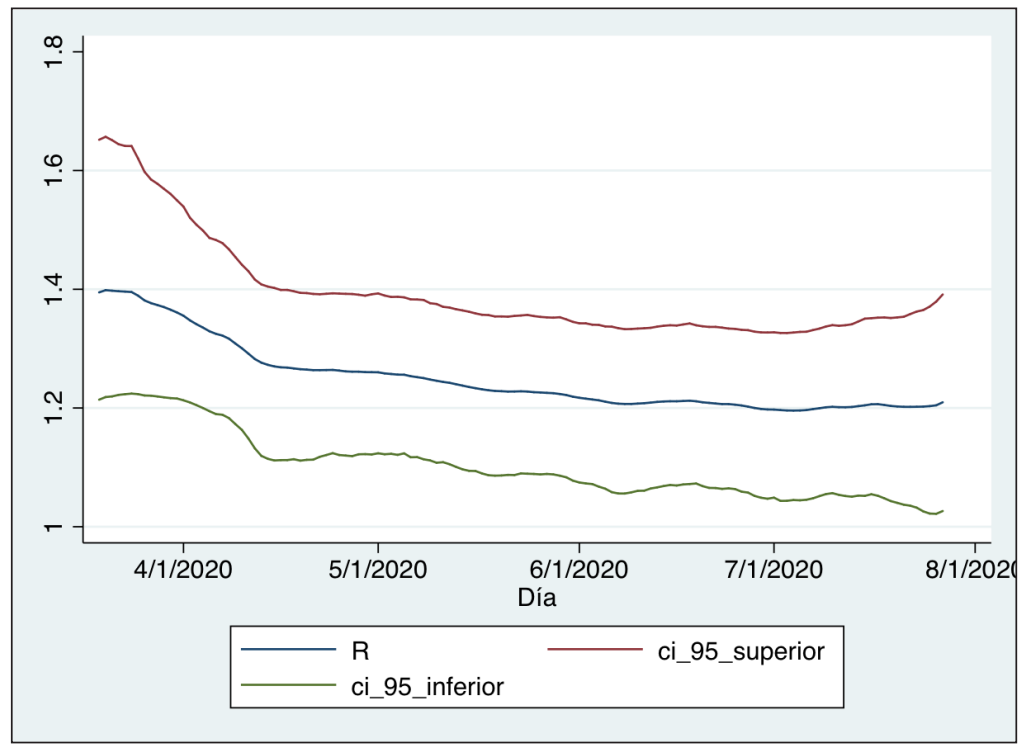

\section{Análisis descriptivo de las tendencias del COVID-19}

Antes de mostrar los resultados de la estimación, la figura 3 presenta las trayectorias de los contagios y muertes por COVID-19 en escala logarítmica y las tendencias recientes seguidas por estas variables mediante la estimación de polinomios locales. Este proceso se realiza utilizando la información reportada oficialmente por el Ministerio de Salud, con el fin de determinar gráficamente los posibles quiebres experimentados para el total nacional y las ciudades seleccionadas.

5 Las estimaciones realizadas por el autor se pueden obtener en tiempo real para todos los países del mundo en: http://trackingr-env.eba-9muars8y.us-east-2.elasticbeanstalk.com. 


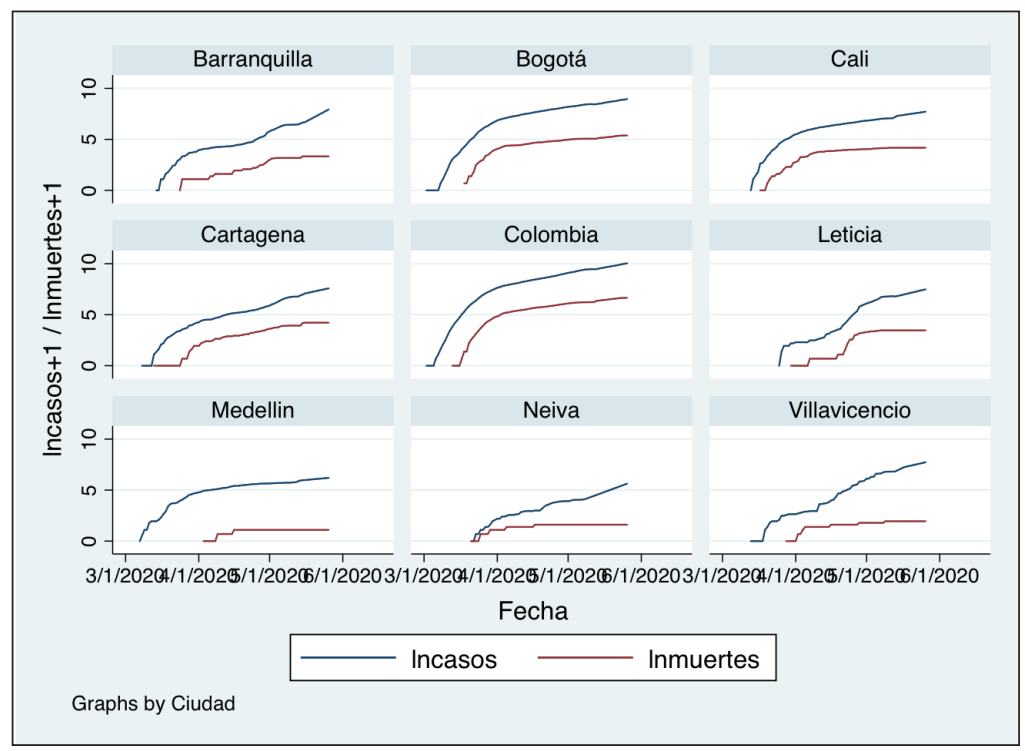

El comportamiento de casos y muertes a nivel nacional y en Bogotá sigue trayectorias similares a pesar de que los niveles son diferentes; esto se debe, en parte, a los tamaños de población. Las tasas de crecimiento promedio día de contagios a nivel nacional y Bogotá son 27,3 y 26,8 \%, respectivamente, lo que implica una expansión veloz del virus en estas regiones. Por su parte, las tasas de crecimiento promedio día de fallecimientos a nivel nacional y Bogotá son 25,5 y 17,9\%, respectivamente. De igual forma, se destaca la dinámica de la tasa de fallecidos en Leticia, ciudad que presenta un crecimiento promedio diario de 22,9\%, una de las más altas después de Bogotá.

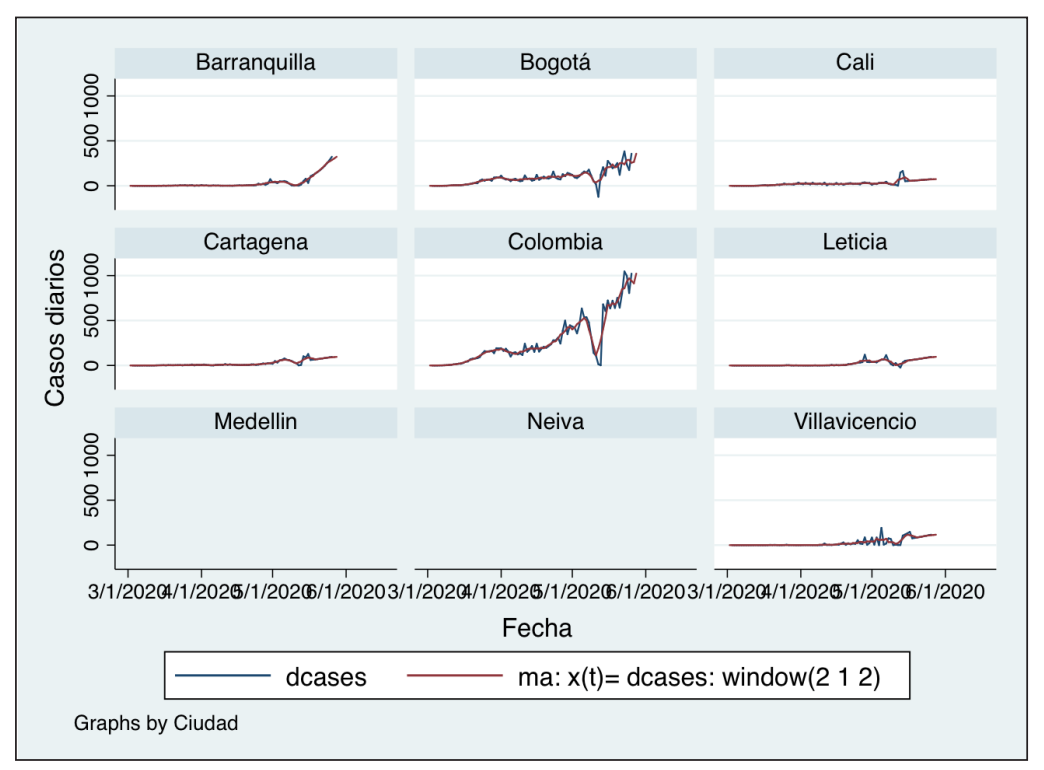

\section{Figura 3.}

Número de contagios y muertes por COVID-19 en Colombia

Fuente: elaboración propia con datos del Ministerio de Salud.

\section{Figura 4.}

Casos diarios de contagios no acumulados y tendencias del COVID-19 
TIEMPO \& ECONOMÍA

Vol. 8 N. ${ }^{\circ} 1$ | Enero - Junio del 2021

pp. $123-160$

Figura 5.

Muertes diarias y tendencias del COVID 19

Fuente: elaboración propia con datos del Ministerio de Salud.

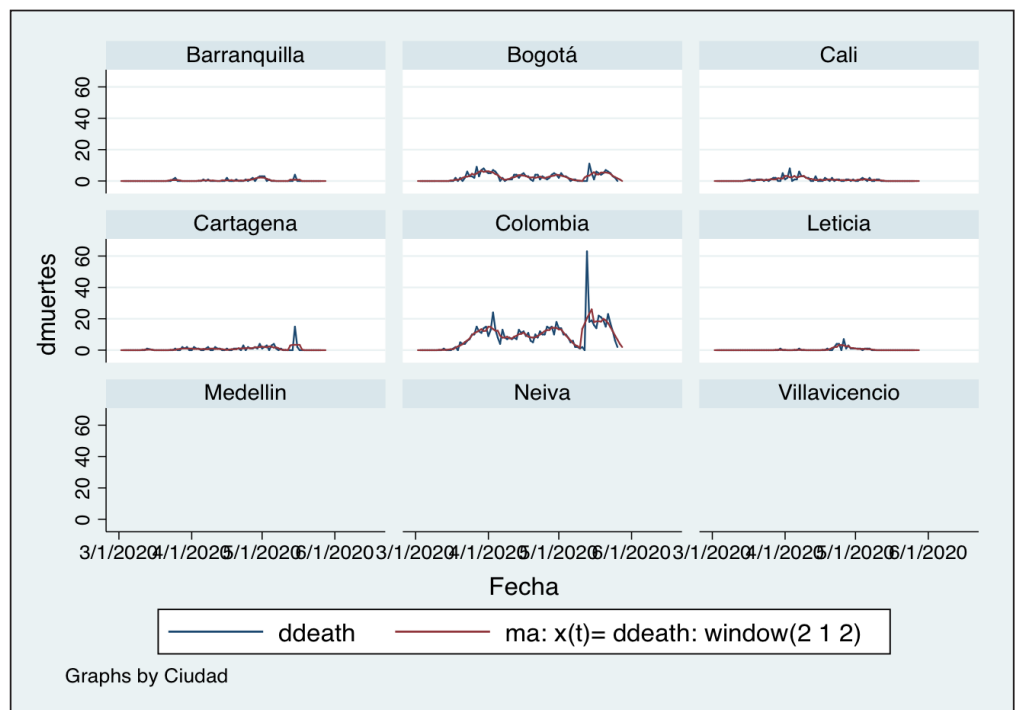

Las figuras 4 y 5 presentan las tendencias de contagios y fallecimientos por COVID-19 y sus respectivas tendencias estimadas por suavizamiento exponencial, destacando el decrecimiento en Bogotá y Colombia, sobre todo a finales del mes de mayo. A partir de la evolución y la tendencia que exhiben los nuevos contagios y muertes, se deduce que la trayectoria se podría representar por modelos cuadráticos susceptibles a ser estimados a partir de la información disponible.

Resulta interesante analizar la evolución de los contagios por el nuevo coronavirus y el número de reproducción efectiva $\left(R_{t}\right)$ discutido en la sección 2. La figura 6 compara la tasa de crecimiento diaria de los casos activos ${ }^{6}$ con el número $R_{t}$ (medido en escala derecha) desde el momento en que se registra el primer caso en el país. Se observa que las dos variables evolucionan en la misma dirección, de tal forma que cuando el valor de $R_{t}$ incrementa así mismo aumenta la velocidad de propagación del virus y existirán más personas contagiadas. Lo anterior evidencia que las medidas de contención de la pandemia a partir de políticas públicas implementadas por el Gobierno debe tener en cuenta la evolución de esta variable. Así mismo, si se quiere extrapolar los casos futuros de contagios y muertes, es necesario tener presente este factor en las ecuaciones o curvas estimadas, tal como se hace en el presente trabajo. 


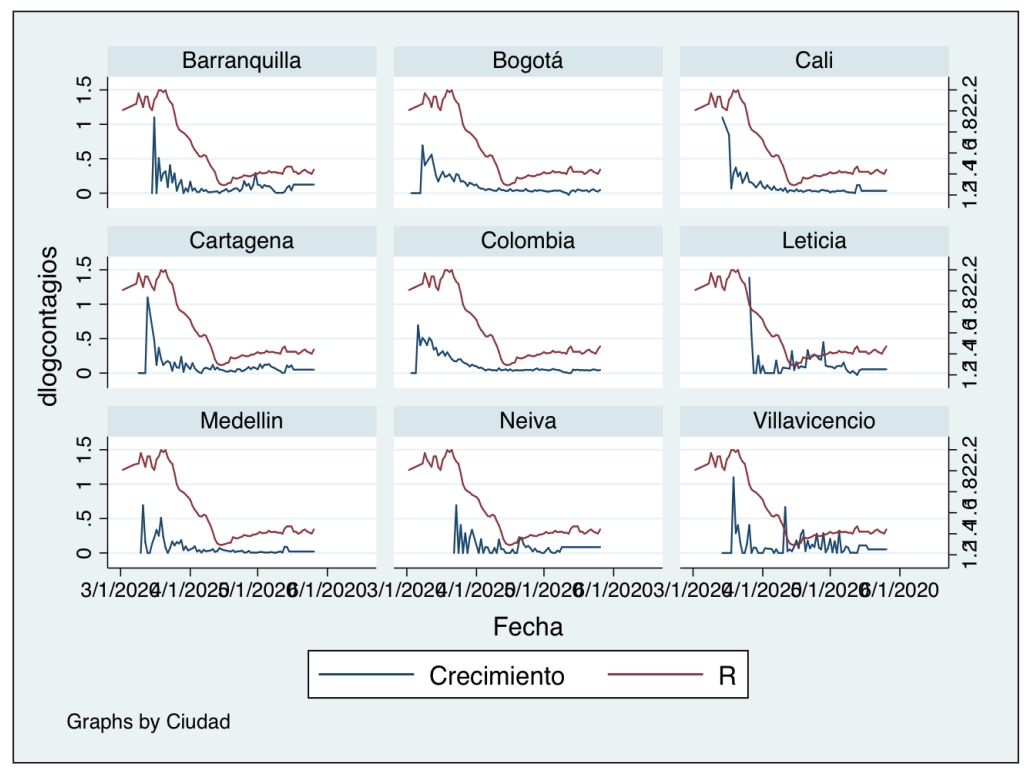

\section{REVISIÓN DE LA LITERATURA}

El fuerte impacto económico que ha tenido la pandemia de COVID-19 ha despertado el interés de los economistas por estudiar y cuantificar sus efectos sobre la economía a partir de modelos de comportamiento del virus y cómo estos se pueden abordar desde los modelos económicos convencionales, para lo cual, metodológicamente, se ha utilizado la econometría (ver Stock [2020] y Avery et al. [2020] para conocer un importante resumen de trabajos en esta línea).

De acuerdo con Fernández-Villaverde y Jones (2020), los economistas han argumentado que muchos de los parámetros de los modelos económicos que recogen el nexo entre diferentes variables económicas no son estructurales, en el sentido de Hurwicz (1962), sino que dependen del comportamiento de los agentes y de las decisiones de política económica. Por ejemplo, la tasa de contactos entre personas que determina el número de nuevas infecciones es función de la oferta laboral, que es endógena, y de las decisiones de consumo de los individuos. En este sentido, la evolución y los efectos del virus pueden ser abordados desde este enfoque, como se hace, por ejemplo, en los trabajos de Eichenbaum et al. (2020) y Farboodi et al. (2020). De igual forma, las tasas de recuperación y muertes por la pandemia, como parámetros clínicos, podrían ser función de decisiones de política pública tales como la expansión de la capacidad hospitalaria o las prioridades en la asignación de pacientes a las diferentes unidades de cuidados intensivos (UCI). Así mismo, la tasa de mortalidad es un parámetro

\section{Figura 6.}

Contagios por COVID-19y número de reproducción efectiva

Fuente: elaboración propia con datos del Ministerio de Salud. 
clave para analizar la severidad de la epidemia. Esta tasa se caracteriza por ser una función compleja de parámetros clínicos y demográficos y de los mecanismos de selección de la enfermedad, los cuales podrían ser el resultado de decisiones endógenas (Korolev, 2020).

El artículo de Fernández-Villaverde y Jones (2020) recoge todas estas ideas con el fin de permitir que las tasas de contagio del COVID-19 estén influenciadas por las políticas de distanciamiento social y por varios parámetros que varían entre países, estados y ciudades, los cuales se constituyen en buenas proxies de la demografía y de la heterogeneidad que existe detrás de la evolución de la pandemia. En este sentido, estos autores parten de los modelos epidemiológicos básicos en tiempo discreto, pero incluyen el efecto de las políticas de distanciamiento social y los calibran de forma que al incorporar estas medidas se pueden realizar simulaciones para la tasa de letalidad en diferentes escenarios. Los autores concluyen que los modelos siguen muy de cerca la dinámica del virus a nivel mundial y que esta se encuentra influenciada por el comportamiento de los individuos y responde a las medidas de política implementadas por los gobiernos.

Otro conjunto de trabajos relacionados con la "economía del COVID-19" se caracterizan porque no estudian problemas relacionados con identificación en los modelos de comportamiento económico; distinguidos por tener un número muy amplio de parámetros que se estiman a partir de los datos observados que, en ocasiones, no son identificados o se encuentran débilmente identificados. De otro lado, algunos investigadores han ignorado por completo el uso de modelos comportamentales y han optado por análisis de series de tiempo para determinar la trayectoria seguida por el nuevo Coronavirus, por ejemplo, los trabajos de Linton y Shaoran (2020), Arroyo-Marioli et al. (2020) y Liu et al. (2020). En efecto, el trabajo de Linton y Shaoran (2020), a partir de la evolución de los casos diarios de COVID-19 en diferentes países del mundo, aplica modelos con tendencia cuadrática con el fin de estimar el momento en donde se alcanza el pico de contagio en términos de nuevos contagios y muertes generadas por el nuevo coronavirus. Este autor encuentra que para el caso del Reino Unido el pico ocurriría en las siguientes dos semanas después de la elaboración de sus estudios y que el número total de caos diarios en el pico sería 8.000.

Un enfoque de investigación de moda por estos días se caracteriza por utilizar modelos comportamentales más sofisticados que involucran múltiples dimensiones. Acemoglu et al. (2020), Alvarez et al. (2020) y Chari et al. 
(2020) describen las políticas óptimas de aislamiento implementadas por un planeador que quiere controlar el número de muertes de una pandemia mientras minimiza los costos asociados a las políticas de aislamiento social. Berger et al. (2020) analizan el impacto de la realización de pruebas para detectar el número de infectados y el efecto de las cuarentenas. Bethune y Korinek (2020) estiman las externalidades negativas derivadas de la pandemia y encuentran que estas son bastante fuertes. Por su parte, Bodenstein et al. (2020) combinan modelos comportamentales con modelos de equilibrio general computable multisectoriales para cuantificar los efectos a partir de matrices insumo-producto para Estados Unidos. Garriga et al. (2020), Hornstein (2020) y Karin et al. (2020) estudian una gran variedad de medidas de contención del virus. Además, Toda (2020) estima modelos epidemiológicos SIR con el fin de estimar la política óptima de mitigación controlando factores como el período y la intensidad del distanciamiento social.

Un gran conjunto de trabajos se ha concentrado en estudiar los efectos macroeconómicos del COVID-19. Ludvigson et al. cuantifican los impactos macroeconómicos de los costos y los desastres mortales en la historia reciente de Estados Unidos a causa del COVID-19. Estos autores construyen una serie de desastres macroeconómicos y estiman un VAR para el período 1980: 1 a 2019: 12, encontrando que los efectos se concentran más en pérdidas de empleo antes que destrucción del stock de capital, afectando principalmente la salud y el bienestar del capital humano. Por su parte, Chang y Velasco (2020) analizan los efectos endógenos de las políticas económicas y de los incentivos implícitos y explícitos que estas ofrecen a partir de un modelo económico de la pandemia que contempla las decisiones que toman los individuos relacionadas con la propagación del virus. Los autores encuentran que la velocidad del virus está influenciada por la política pública vía incentivos, y que las políticas de salud pública y las políticas macroeconómicas pueden ser complementadas con el fin de reducir los costos de la pandemia y la reducción de la propagación del virus. Lin y Meissner (2020) estudian el impacto de las políticas de intervención no farmacéuticas como "quedarse en casa" (cuarentena) sobre la velocidad de propagación del virus, identificando que las políticas locales tienen un pequeño impacto sobre la economía, contrario al efecto generado por las políticas de salud. Por otro lado, estos autores también encuentran que existe una relación muy débil entre la cuarentena y la propagación del virus - que está más relacionada con una mayor actividad residencial- y que los spillovers derivados de la 
política económica y respuestas comportamentales son muy importantes para la contención del virus.

Aum et al. (2020) construyen el modelo cuantitativo de una economía golpeada por una pandemia en donde los agentes difieren en edades y habilidades y eligen sus ocupaciones con el fin de maximizar su ingreso y minimizar el miedo a la infección. A partir de la calibración del modelo, estos autores replican la propagación del COVID-19 en Corea del Sur y Reino Unido, hallando que las medidas de aislamiento no presentan un claro trade off entre el PIB y las políticas de salud, como comúnmente se cree. Además, encuentran que si el gobierno del Reino Unido hubiera adoptado las políticas implementadas por Corea del Sur, las pérdidas en producción (PIB) y el aumento en el número de contagios podrían haber sido sustancialmente menores tanto en el corto como en el largo plazo.

Gregory et al. (2020) desarrollan y calibran un modelo de búsqueda de trabajo con el fin de pronosticar la evolución del mercado laboral de Estados Unidos durante y después de la pandemia. El modelo está diseñado de tal forma que permite capturar la heterogeneidad de transición de los trabajadores en los estados de empleo-desempleo y entre diferentes empleadores. Los resultados muestran que las medidas de aislamiento encaminadas a contener la propagación del nuevo coronavirus generan importantes efectos negativos sobre la tasa de desempleo debido a la dificultad de recuperar los empleos perdidos por aquellos trabajadores que han tomado años en conseguirlos.

Para el caso colombiano existen varias investigaciones que intentan medir el impacto del nuevo coronavirus sobre la economía y la evaluación de las medidas de aislamiento. El trabajo de Cordovez et al. (2020) utiliza un modelo matemático para estudiar la dinámica de contagio del COVID-19 en un ambiente urbano realista y evaluar el efecto que pueden tener las medidas de mitigación de la propagación del nuevo coronavirus en Bogotá. Igualmente, estos autores evalúan el efecto de abrir gradualmente sectores de la economía y la reapertura de colegios (públicos y privados) y universidades sobre el sistema de salud y el posible rebrote de la infección después del período de análisis. El estudio encuentra que las medidas de mitigación implementadas permiten aplazar el crecimiento exponencial de los contagios, pero no evitan que se exceda la capacidad de camas en las UCI. Por otro lado, la duración de la restricción en el tiempo o la proporción de personas que cobija la norma tienen siempre el mismo efecto de desplazar la curva 
de contagios en el tiempo. Así mismo, el cierre de universidades y colegios es menos eficiente en aplacar el crecimiento de la curva comparado con la restricción de la movilidad de adultos. Otros resultados importantes de este trabajo señalan que los efectos de restringir los sectores económicos son determinantes para no exceder la capacidad del sistema de salud en el mes de junio y que una restricción de la economía que genere una disminución de la movilidad durante el mes de junio de $60 \%$ es lo mínimo para no exceder la oferta de UCI.

Por otra parte, el trabajo de Álvarez et al. (2020) presenta una descripción de la situación de la propagación del COVID-19 en Colombia, a partir de la cual formulan propuestas de política con el fin de contener el contagio y ajustar la infraestructura de salud, mitigar los efectos nocivos de la crisis sobre la incidencia de la pobreza y proteger el empleo formal para ayudar a la supervivencia de las firmas. Los autores concluyen que el confinamiento fue una medida necesaria para suavizar el aumento de la tasa de contagios y preparar la infraestructura de salud para encarar efectos adversos. Así mismo, afirman que mientras dure el confinamiento será necesario realizar transferencias monetarias no condicionadas suficientes a los hogares que se ven afectados por la parálisis.

De otro lado, Bardey et al. (2020) realizan un análisis gráfico del impacto potencial de medidas de contención tales como el confinamiento y restricciones a la movilidad. A partir de la estimación de correlaciones entre la diferencia de logaritmos (tasa de crecimiento) de los casos acumulados de nuevos contagios y el número de muertes, estos investigadores encuentran que dichas políticas producen efectos inmediatos sobre el crecimiento de los casos de contagio y la tasa de crecimiento del número de muertes, las cuales han sufrido un retraso después de las medidas implementadas. De acuerdo con los autores, el análisis gráfico es consistente con las características epidemiológicas del virus y sugiere que las políticas implementadas han tenido un efecto significativo sobre la tasa de crecimiento de nuevos contagios y el número de muertes.

Un enfoque regional de los efectos del nuevo coronavirus sobre la actividad económica se presenta en el trabajo de Bonet-Morón et al. (2020). El estudio evalúa el impacto económico regional y sectorial de las medidas de aislamiento preventivo ordenadas por el Gobierno Nacional para evitar los efectos nocivos del nuevo coronavirus. A partir de un modelo de insumo-producto, los autores estiman la pérdida económica en términos 
de empleos formales e informales en distintos sectores de la economía. Los resultados muestran que las pérdidas oscilan entre 4,6 y 59 billones de pesos colombianos por mes, de acuerdo con los escenarios considerados, las cuales representan entre 0,5 y 6,1 \% del PIB nacional. Los departamentos de Antioquia, Boyacá, San Andrés, Santander y Valle del Cauca aparecen como los más afectados.

\section{MODELACIÓN DE LA DINÁMICA DEL COVID-19}

Esta sección sigue de cerca el modelamiento presentado por Linton y Shaoran (2020), aunque incorpora una ligera diferencia relacionada con la introducción de un vector de regresores adicionales que explican la trayectoria futura de los nuevos casos, como, por ejemplo, la evolución del número de reproducción efectiva, ya explicado en la sección 2.

En este trabajo se utilizan datos diarios de nuevos casos de contagios y muertes a partir de la información suministrada oficialmente por el Ministerio de Salud. De acuerdo con esta información, el primer caso en Colombia se registró el 6 de marzo de 2020 (día 1). La información permite tener nuevos casos diarios de contagios y muertes hasta el 27 de mayo de 2020, lo cual representa 81 días desde el primer caso. Con base en esta información, la trayectoria de los nuevos casos se puede modelar a partir de la siguiente ecuación:

$$
\ln \left(y_{i t}+1\right)=z_{i}(t)+\theta_{i} X_{i t}+\varepsilon_{i t} \quad(\text { Ec. 7) }
$$

En donde $z_{i}$ es la tendencia, $y_{i t}$ el número de nuevos casos o nuevas muertes en la ciudad $i, X_{i t}$ es un vector de variables regresoras, tales como el número de reproducción efectivo, y $\varepsilon_{i t}$ el término de error con valor esperado igual a cero.' La ecuación 7 se estima a partir de una estructura de datos de corte longitudinal a nivel de ciudad por diferentes métodos, tal como se expondrá en la siguiente sección.

7 Sumar uno (1) al número de casos nuevos solo es necesario para algunas ciudades que tienen un registro de datos muy dispersos, o cuando al comienzo de la pandemia existían ausencia de datos, es decir, eran iguales a cero. 


\section{La ecuación cuadrática}

Con el fin de estimar y predecir el futuro pico de contagios y muertes por el nuevo coronavirus, se utiliza un modelo cuadrático que presenta la siguiente forma:

$$
z_{i}(t)=\phi+\beta t+\gamma t^{2} \quad(\text { Ec. } 8)
$$

La expresión mostrada en la ecuación 8 es el modelo cuadrático más simple que captura la evolución del COVID-19 (figuras 4 y 5) y permite la estimación de los puntos de inflexión (turning points), los cuales podrían ser interpretados como una aproximación local a través del suavizamiento de la variable mediante la estimación de polinomios locales de grado 2. En la ecuación 8 la tendencia promedio será la suma de los parámetros que acompañan al término lineal y cuadrático de la ecuación, es decir, $\beta+\gamma$. El máximo local de la función $z_{i}$ tendrá lugar cuando $\gamma<0$ y sucede en el momento $\left.t_{\text {max }}=-\beta\right) 2 \gamma^{8}$, que al ser reemplazado permite obtener el número máximo de casos diarios $z_{i} t_{\max }=\phi-\beta^{2 / 4}$. Finalmente, el valor de $t$ después del cual ningún caso podría ser reportado (fin de la pandemia) será igual a la raíz más grande de $z_{i}(t)=0$. De manera intuitiva, se puede identificar el punto de inflexión de la función $z_{i}(t)$ a partir de la curvatura de la función de regresión cuando se alcanza el punto de quiebre.

La muestra para la estructura de datos de panel a nivel de ciudades está conformada por 8 ciudades, más Colombia, para un total de 9 unidades de sección cruzada. ${ }^{9}$ La selección de estas ciudades se basó en el criterio de ser aquellas con el mayor número de casos reportados y por el hecho de presentar el mayor crecimiento de casos a nivel nacional.

La tabla 1 presenta un conjunto de estadísticas descriptivas para las principales ciudades y el total nacional de los datos más recientes de nuevos contagios y muertes. Se destaca el número promedio de contagios y muertes de Bogotá, Cali, Villavicencio y Cartagena. La ciudad con el menor número de contagios y muertes, hasta el momento, sigue siendo Medellín.

8 La obtención del máximo local se consigue simplemente al obtener la condición de primer orden e igualando a cero, es decir, calcular la derivada parcial de $z_{i}(t)$ cuando cambia $\partial z_{i}$ $(\mathrm{t}) / \partial t=\beta+2 \gamma t=0$.

9 Se tiene un panel de datos largo que se caracteriza porque el número de unidades de sección cruzada (ciudades) es menor a la dimensión temporal ( 85 días), lo cual es favorable debido a que permite capturar la dinámica del virus y la estimación recursiva de las tendencias. 
TIEMPO \& ECONOMÍA Vol. 8 N. ${ }^{\circ} 1$ | Enero - Junio del 2021 pp. $123-160$

Tabla 1. Estadísticas descriptivas sobre COVID-19

Fuente: elaboración propia con datos del Ministerio de Salud.

\begin{tabular}{|c|c|c|c|c|c|c|c|c|c|c|c|c|c|c|c|}
\hline \multirow[b]{2}{*}{ Variables } & \multicolumn{5}{|c|}{ Barranquilla } & \multicolumn{5}{|c|}{ Bogotá } & \multicolumn{5}{|c|}{ Cali } \\
\hline & $\mathrm{N}$ & mean & Max & Min & Stdv & $\mathrm{N}$ & Mean & Max & Min & Stdv & $\mathrm{N}$ & Mean & Max & Min & Stdv \\
\hline Casos & 85 & 346 & 2,774 & 0 & 0 & 85 & 2,394 & 7,743 & 1 & 1 & 85 & 662.1 & 2,228 & 0 & 0 \\
\hline Fallec & 85 & 10,46 & 28 & 0 & 0 & 85 & 92.58 & 218 & 0 & 0 & 85 & 35.74 & 65 & 0 & 0 \\
\hline $\mathbf{R}$ & 85 & 1.643 & 2.197 & 1.29 & 1.293 & 85 & 1.632 & 2.197 & 1.29 & 1.293 & 85 & 1.632 & 2.197 & 1.293 & 1.29 \\
\hline \multirow[t]{2}{*}{ Grupos } & 9 & 9 & 9 & 9 & 9 & 9 & 9 & 9 & 9 & 9 & 9 & 9 & 9 & 9 & 9 \\
\hline & \multicolumn{5}{|c|}{ Cartagena } & \multicolumn{5}{|c|}{ Colombia } & \multicolumn{5}{|c|}{ Leticia } \\
\hline Variables & $\mathrm{N}$ & mean & Max & Min & Stdv & $\mathrm{N}$ & Mean & Max & Min & Stdv & $\mathrm{N}$ & Mean & Max & Min & Stdv \\
\hline Casos & 85 & 394.7 & 1,968 & 0 & 0 & 86 & 6,218 & 23,003 & 1 & 1 & 86 & 336.6 & 1,791 & 0 & 0 \\
\hline Fallec & 85 & 24.58 & 68 & 0 & 0 & 86 & 284.3 & 776 & 0 & 0 & 86 & 11.76 & 32 & 0 & 0 \\
\hline $\mathbf{R}$ & 85 & 1.632 & 2.197 & 1.29 & 1.293 & 86 & 1.639 & 2.197 & 1.29 & 1.293 & 86 & 1.639 & 2.197 & 1.293 & 1.29 \\
\hline \multirow[t]{2}{*}{ Grupos } & 9 & 9 & 9 & 9 & 9 & 9 & 9 & 9 & 9 & 9 & 9 & 9 & 9 & 9 & 9 \\
\hline & \multicolumn{5}{|c|}{ Medellín } & \multicolumn{5}{|c|}{ Neiva } & \multicolumn{5}{|c|}{ Villavicencio } \\
\hline Variables & $\mathrm{N}$ & mean & Max & Min & Stdv & $\mathrm{N}$ & Mean & Max & Min & Stdv & $\mathrm{N}$ & Mean & Max & Min & Stdv \\
\hline Casos & 84 & 197.8 & 491.7 & 0 & 0 & 84 & 46.37 & 278.6 & 0 & 0 & 86 & 400.5 & 2,270 & 0 & 0 \\
\hline Fallec & 84 & 1.667 & 3 & 0 & 0 & 84 & 3.31 & 5 & 0 & 0 & 86 & 3.581 & 7 & 0 & 0 \\
\hline $\mathbf{R}$ & 84 & 1.636 & 2.197 & 1.29 & 1.293 & 84 & 1.636 & 2.197 & 1.29 & 1.293 & 86 & 1.639 & 2.197 & 1.293 & 1.29 \\
\hline Grupos & 9 & 9 & 9 & 9 & 9 & 9 & 9 & 9 & 9 & 9 & 9 & 9 & 9 & 9 & 9 \\
\hline
\end{tabular}

\section{Estimación del punto de inflexión (turning point)}

Con el fin de estimar y predecir el momento en que tiene lugar el pico y el número máximo de contagios y muertes, la estrategia de estimación que se siguió fue la siguiente: En primer lugar, se realizó la estimación dentro de la muestra con los datos más recientes, es decir, seleccionando una ventana de 30 observaciones y se verifica que el signo del parámetro estimado que acompaña al término cuadrático de la ecuación sea menor que cero, $\hat{y}<0$. Después, se reemplaza el valor de $\hat{y}$ en la ecuación con el fin de encontrar el máximo número de casos al interior de la muestra.

Finalmente, para predecir el pico de infección fuera de muestra, se realizan pronósticos para cada una de las ciudades de manera separada y se realiza la estimación rolling window con la estructura de datos de panel identificando el máximo número de casos y el momento en que este tiene lugar. 


\begin{tabular}{|c|c|c|c|c|c|c|c|c|c|}
\hline \multicolumn{10}{|c|}{ Ventana de 30 días iniciando el día 27 de mayo hasta el 27 de junio de 2020} \\
\hline Parámetros & B/quilla & Bogotá & Cali & C/gena & Colombia & Leticia & Medellín & Neiva & V/vicencio \\
\hline R2 & 0.951 & 0.997 & 0.995 & 0.994 & 0.997 & 0.988 & 0.985 & 0.981 & 0.912 \\
\hline b_t & 0.0549 & 0.0482 & 0.0604 & 0.0771 & 0.0558 & 0.124 & 0.0306 & 0.0788 & 0.0442 \\
\hline - b_t2 & $0.000326^{* * *}$ & $-0.000258^{* * *}$ & $-0.000485^{* * *}$ & $-4.38 \mathrm{e}-05^{* * *}$ & $-0.000198^{* * *}$ & $0.000268^{* * *}$ & $-0.000168^{* * *}$ & $-0.000487^{* * *}$ & $0.000901^{* * *}$ \\
\hline b_ $R$ & -2.011 & -0.263 & 0.172 & -0.333 & -0.209 & -0.394 & 0.136 & 0.966 & -3.805 \\
\hline _b_cons & 6.586 & 7.214 & 5.024 & 4.122 & 7.746 & 2.631 & 4.728 & 0.388 & 9.43 \\
\hline \multicolumn{10}{|c|}{ Ventana de 50 días iniciando el día 1 de junio hasta el 5 de julio de 2020} \\
\hline Parámetros & B/quilla & Bogotá & Cali & C/gena & Colombia & Leticia & Medellín & Neiva & V/vicencio \\
\hline R2 & 0.98 & 0.997 & 0.995 & 0.994 & 0.997 & 0.987 & 0.983 & 0.984 & 0.914 \\
\hline b_t & 0.0642 & 0.0484 & 0.0529 & 0.0586 & 0.0533 & 0.139 & 0.0324 & 0.0723 & 0.093 \\
\hline b_t2 & $0.000266^{* *}$ & $-0.000287^{* * *}$ & $-0.000442^{* *}$ & $0.000212^{* *}$ & $-0.000200^{* * *}$ & $0.000182^{* * *}$ & $-0.000179^{* *}$ & $-0.000486^{* *}$ & $0.000406^{* * *}$ \\
\hline b_R $R$ & -0.968 & -0.0239 & -0.00324 & -0.428 & 0.156 & 2.173 & -0.386 & 1.12 & -1.801 \\
\hline _b_cons & 4.764 & 6.935 & 5.511 & 4.512 & 7.356 & -1.465 & 5.398 & 0.53 & 5.56 \\
\hline \multicolumn{10}{|c|}{ Ventana de 60 días iniciando el día 12 de mayo hasta el 15 de julio de 2020} \\
\hline Parámetros & B/quilla & Bogotá & Cali & C/gena & Colombia & Leticia & Medellín & Neiva & V/vicencio \\
\hline -R2 & 0.981 & 0.998 & 0.995 & 0.995 & 0.998 & 0.986 & 0.986 & 0.984 & 0.947 \\
\hline b_t & 0.0682 & 0.0478 & 0.0465 & 0.0509 & 0.0523 & 0.168 & 0.0307 & 0.0744 & 0.13 \\
\hline - b_t2 & $0.000273^{* * *}$ & $-0.000258^{* * *}$ & $-0.000296^{* * *}$ & $0.000311^{* * *}$ & $-0.000169^{* * *}$ & $-0.000372^{* * *}$ & $-0.000175^{* * *}$ & $-0.000422^{* *}$ & $-0.000168^{* * *}$ \\
\hline b_ $R$ & -0.235 & -0.0336 & -0.169 & -0.573 & 0.148 & 3.099 & -0.455 & 1.127 & -0.348 \\
\hline b_cons & 3.647 & 6.968 & 5.862 & 4.875 & 7.396 & -3.211 & 5.547 & 0.501 & 2.832 \\
\hline
\end{tabular}

El método de estimación recursiva por rolling window permite que los parámetros de la ecuación 8 cambien a través del tiempo y entre ciudades, lo cual se puede percibir en la tabla 2. Los resultados muestran un buen ajuste de las estimaciones, como se evidencia en los altos valores del $R^{2}$ para todas las ciudades. Los valores estimados del parámetro que acompaña al término cuadrático del tiempo (_b_t2) tiene el signo negativo esperado, lo que implica la presencia de un máximo local en las unidades de sección cruzada de la estructura de datos de panel y que, además, son estadísticamente significativos y diferentes a cero. No obstante, el signo negativo depende de la ventana escogida en la estimación recursiva. Por ejemplo, para una ventana de 30 días iniciando el 27 de mayo, el pico de contagio se alcanzaría el próximo 27 de junio en la mayoría de ciudades, incluida Colombia, excepto en Barranquilla, Leticia y Villavicencio. Cuando se escoge una ventana de 50 días iniciando el 1 de junio, el pico de contagio se alcanzaría el próximo 5 de julio en Bogotá, Cali, Colombia, Medellín y Neiva, mientras que en Barranquilla, Cartagena y Leticia se esperaría un pico mucho más alto.

La tabla 3 presenta los resultados de la estimación de la ecuación cuadrática de forma recursiva usando la técnica de rolling window para el logaritmo de fallecidos.
Tabla 2.

Estimación de la ecuación cuadrática de forma recursiva por rolling window (variable dependiente: logaritmo de contagios)

${ }^{* * *} p<0.001,{ }^{* *} p<0.05$ Fuente: elaboración propia con datos del Ministerio de Salud. 
TIEMPO \& ECONOMÍA Vol. 8 N. ${ }^{\circ} 1$ | Enero - Junio del 2021 pp. $123-160$

Tabla 3.

Estimación de la ecuación cuadrática de forma recursiva por rolling window (variable dependiente: logaritmo de fallecidos)

${ }^{* * *} \mathrm{p}<0.001,{ }^{* *} \mathrm{p}<0.05$ Fuente: elaboración propia con datos del Ministerio de Salud.

\begin{tabular}{|c|c|c|c|c|c|c|c|c|c|}
\hline \multicolumn{10}{|c|}{ Ventana de 30 días iniciando el día 27 de mayo hasta el 27 de junio de 2020} \\
\hline Parámetros & B/quilla & Bogotá & Cali & C/gena & Colombia & Leticia & Medellín & Neiva & V/vicencio \\
\hline -R2 & 0.915 & 0.981 & 0.932 & 0.967 & 0.989 & 0.909 & 0.886 & 0.79 & 0.885 \\
\hline b_t $\mathrm{t}$ & 0.0811 & 0.0389 & 0.0841 & 0.0877 & 0.0597 & 0.155 & 0.0969 & 0.0184 & 0.0442 \\
\hline - b_t2 & $0.0000538^{* * *}$ & $-0.00117^{* *}$ & $-0.00393^{* *}$ & $-0.00201^{* * *}$ & $-0.00181^{* * *}$ & $-0.00155^{* * *}$ & $-0.00669^{* * *}$ & $0.000222^{* * *}$ & $-0.000791^{* *}$ \\
\hline b_R $R$ & 1.105 & -0.153 & 0.406 & 1.098 & -0.0164 & 1.393 & 0.595 & 0.128 & -0.348 \\
\hline _b_cons & -0.75 & 4.452 & 2.733 & 0.302 & 5.061 & -3.353 & -0.019 & 1.353 & 1.925 \\
\hline \multicolumn{10}{|c|}{ Ventana de 50 días iniciando el día 1 de junio hasta el 5 de julio de 2020} \\
\hline Parámetros & B/quilla & Bogotá & Cali & C/gena & Colombia & Leticia & Medellín & Neiva & V/vicencio \\
\hline -R2 & 0.949 & 0.981 & 0.9 & 0.976 & 0.991 & 0.934 & 0.896 & 0.798 & 0.833 \\
\hline b_t & 0.0788 & 0.0336 & 0.0601 & 0.0649 & 0.0497 & 0.133 & 0.0447 & 0.0263 & 0.0669 \\
\hline - b_t2 & $-0.000348^{* * *}$ & $-0.00056^{* * *}$ & $-0.0014^{* * *}$ & $-0.000692^{* * *}$ & $-0.000721^{* * *}$ & $-0.00095 * * *$ & $-0.00151^{* * *}$ & $-0.000629^{* * *}$ & $-0.00222^{* * *}$ \\
\hline -b_R & 1.533 & -0.16 & -0.0866 & $0.803 \mathrm{~s}$ & -0.251 & 5.114 & -0.0102 & 0.142 & 0.0634 \\
\hline _b_cons & -1.207 & 4.425 & 3.429 & 0.878 & 5.346 & -7.235 & 1.03 & 1.267 & 1.096 \\
\hline \multicolumn{10}{|c|}{ Ventana de 60 días iniciando el día 12 de mayo hasta el 15 de julio de 2020} \\
\hline Parámetros & B/quilla & Bogotá & Cali & C/gena & Colombia & Leticia & Medellín & Neiva & V/vicencio \\
\hline$-\mathrm{R} 2$ & 0.96 & 0.982 & 0.936 & 0.981 & 0.991 & 0.939 & 0.898 & 0.803 & 0.848 \\
\hline b_t & 0.0795 & 0.0313 & 0.0561 & 0.057 & 0.0472 & 0.147 & 0.0466 & 0.0253 & 0.0574 \\
\hline - b_t2 & $-0.000508^{* * *}$ & $-0.000272^{* * *}$ & $-0.00115^{* * *}$ & $-0.000431^{* *}$ & $-0.000471^{* * *}$ & $-0.00134^{* * *}$ & $-0.0011^{*}$ & $-0.000471^{* * *}$ & $-0.00129^{* * *}$ \\
\hline b_R $R$ & 1.396 & -0.089 & -0.215 & 0.5 & -0.191 & 5.26 & -0.00603 & 0.142 & 0.119 \\
\hline _b_cons & -1.003 & 4.329 & 3.584 & 1.435 & 5.265 & -7.658 & 0.863 & 1.242 & 0.979 \\
\hline
\end{tabular}

Los resultados muestran un buen ajuste de la ecuación cuadrática a los datos observados, lo cual se evidencia en los altos valores del $R^{2}$ en todas las ecuaciones de las ciudades. Los valores estimados del parámetro que acompaña al término cuadrático del tiempo (_b_t2) tienen el signo negativo esperado, lo que muestra que muy pronto se presentará un máximo local para la curva de fallecidos en las unidades de sección cruzada de la estructura de datos de panel, siendo además estadísticamente significativos y diferentes a cero. Como en el caso de la curva de contagios, el signo negativo depende de la escogencia de la ventana en la estimación recursiva. Por ejemplo, para una ventana de 30 días iniciando el 27 de mayo, el pico de fallecidos se alcanzaría el próximo 27 de junio en la mayoría de ciudades, incluida Colombia, excepto en Barranquilla y Neiva. Al escoger una ventana de 50 días que inicia el 1 de junio, el pico de fallecidos se alcanzaría a comienzos de julio en todas las ciudades. El mismo resultado se obtiene cundo se escoge una ventana de tiempo mucho más amplia, por ejemplo de 60 días, la cual comienza el 12 de mayo, en cuyo caso el pico se alcanzaría en la mayoría de unidades de sección cruzada, incluida Colombia, el día 15 de julio. Es importante resaltar que el registro de datos oficiales para contagios y fallecidos está sujeto a márgenes de error asociados al rezago que se presenta en el 
momento de realizar las pruebas y el momento en que se tiene los resultados, que en el caso de Colombia es aproximadamente 10 días, lo cual podría afectar las estimaciones de los máximos alcanzados en el punto de inflexión (turning point).

Las figuras 7 y 8 presentan la evolución en el tiempo de los parámetros estimados de manera recursiva por rolling window para el término cuadrático en las ecuaciones de contagios y fallecidos, con sus correspondientes intervalos de confianza. La trayectoria del parámetro estimado del término cuadrático en la ecuación de fallecidos se encuentra dentro de los límites inferior y superior construidos a partir de un nivel de confianza de $95 \%$, capturando muy bien la dinámica de los máximos alcanzados, sobre todo para las ciudades de Barranquilla, Neiva, Leticia y Villavicencio. En particular, para Leticia y Villavicencio, las figuras evidencian dos puntos de inflexión, lo que podría indicar posiblemente un rebrote del virus después del mes de agosto, resultado que es acorde con el trabajo de Cordovez et al. (2020), quienes encuentran que para evitar una segunda ola que exceda la capacidad del sistema, la ciudad debe llegar a $40 \%$ de recuperados (asumiendo generación de inmunidad). Esta cifra solo se logra permitiendo que las infecciones estén alrededor de 40 infectados por 100.000 habitantes por día durante los tres meses siguientes al mes de agosto.

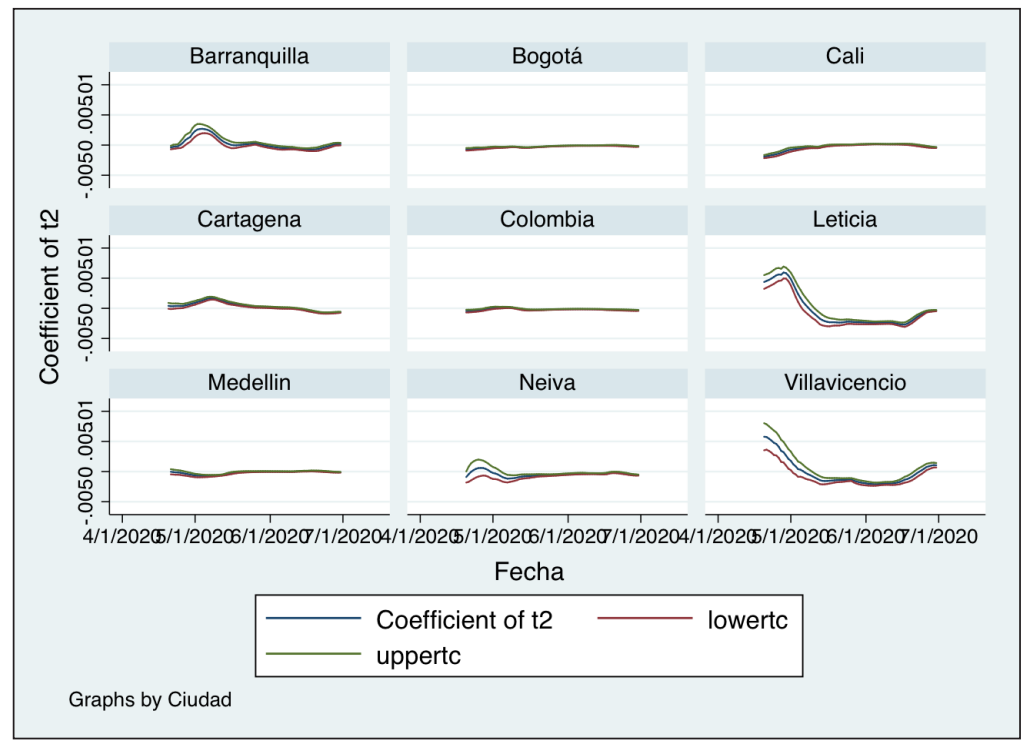

La figura 8 presenta la evolución en el tiempo del parámetro estimado del término cuadrático en la ecuación de fallecidos, el cual se encuentra dentro de los correspondientes intervalos de confianza al 95 \%. La evolución
Figura 7.

Parámetro estimado del término cuadrático (ecuación de contagios)

Fuente: elaboración propia con datos del Ministerio de Salud. 
TIEMPO \& ECONOMÍA

Vol. 8 N. ${ }^{\circ} 1$ | Enero - Junio del 2021 pp. $123-160$

Figura 8.

Parámetro estimado del término cuadrático (ecuación de fallecidos)

Fuente: elaboración propia con datos del Ministerio de Salud.
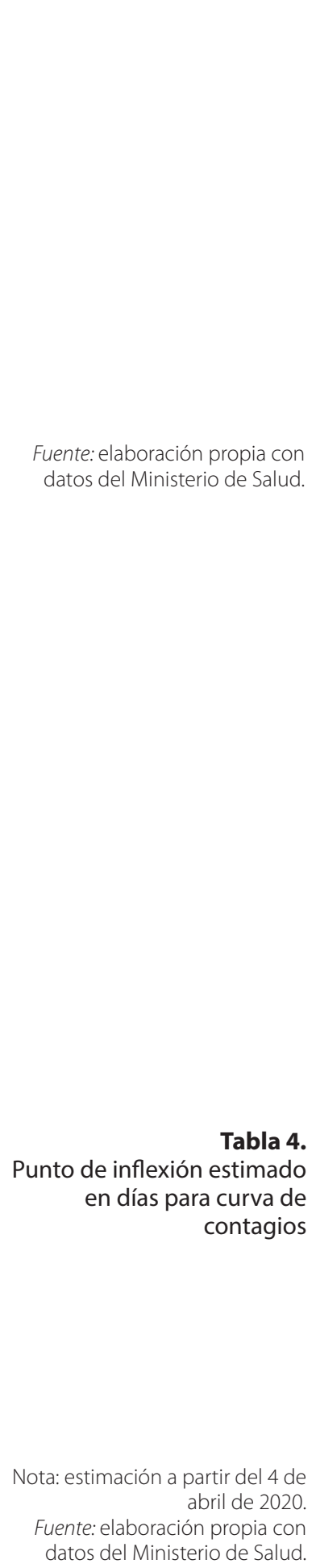

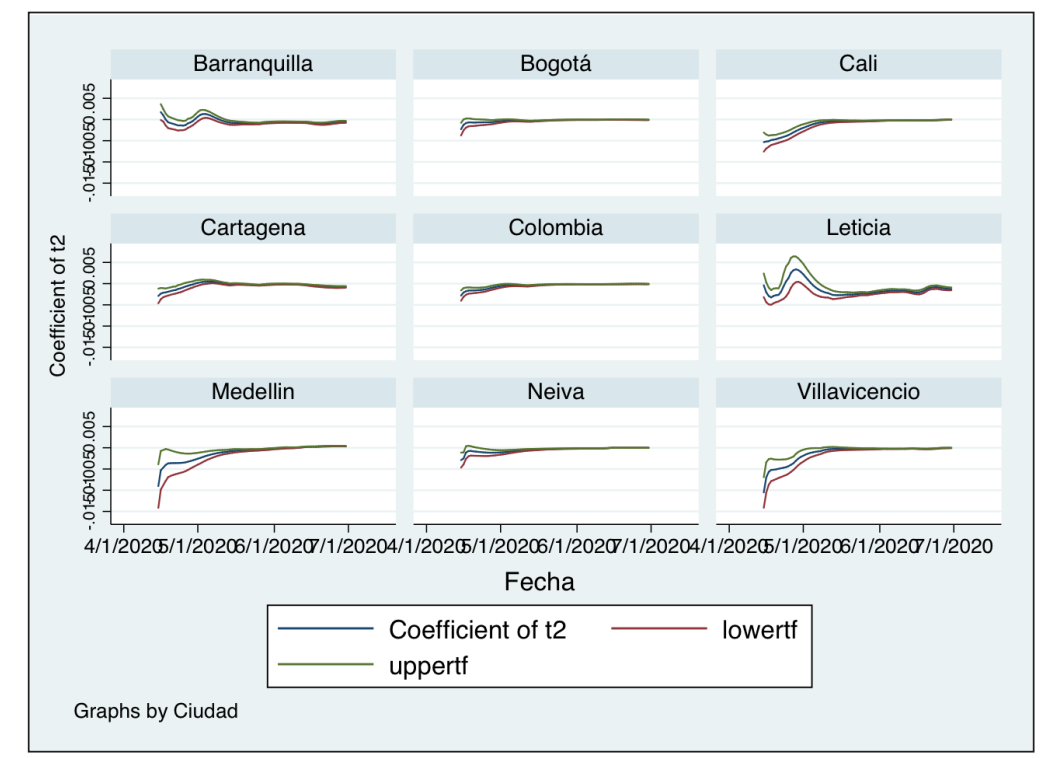

del parámetro es consistente con el pico alcanzado en un lapso de 7 semanas a partir del inicio de la ventana de estimación, que es el 27 de mayo, y es muy marcado en el caso de Leticia, donde al parecer existen por lo menos dos puntos de inflexión.

La tabla 4 presenta la estimación del punto de quiebre en la curva de contagios para las unidades de sección cruzada seleccionadas cuando el parámetro estimado $(\hat{y}<0)$ que acompaña al término cuadrático de la ecuación 8 de nuevos contagios es negativo. Así mismo, esta presenta el punto de inflexión (tmax) que se alcanza cuando el parámetro estimado que acompaña al término cuadrático resulta ser negativo, junto con sus correspondientes intervalos de confianza al $95 \%$.

\begin{tabular}{|c|c|c|c|c|c|c|c|c|c|}
\hline Variables & Barranquilla & Bogotá & Cali & C/gena & Colombia & Leticia & Medellín & Neiva & V/vicencio \\
\hline Tmax & 134.5 & 142 & 55.77 & 6.384 & 72.8 & 42.23 & 112 & 100.5 & 65.19 \\
\hline Inferiort & 128.3 & 135.8 & 62 & 4.153 & 66.57 & 36 & 110 & 94.23 & 58.96 \\
\hline Superiort & 140.7 & 148.2 & 49.54 & 12.61 & 79.03 & 48.46 & 123 & 106.7 & 71.42 \\
\hline \multicolumn{7}{|c|}{ Número máximo de contagios en el pico estimado* } \\
\hline Variables & Barranquilla & Bogotá & Cali & C/gena & Colombia & Leticia & Medellín & Neiva & V/vicencio \\
\hline Zmax & 9.186 & 10.03 & 5.521 & 6.28 & 9.587 & 7.449 & 1.93 & 4.073 & 7.149 \\
\hline Inferiorz & 7.032 & 8.187 & 1.325 & 0.566 & 2.74 & 5.397 & 1.24 & 2.774 & 5.303 \\
\hline Superiorz & 10.661 & 11.03 & 12.37 & 13.13 & 16.43 & 8.296 & 1.61 & 10.92 & 14 \\
\hline
\end{tabular}


A nivel nacional, el pico se alcanzaría aproximadamente en 73 días (18 de agosto $)^{10}$ cuando la ventana de estimación comienza el 8 de junio, con un valor máximo de 80 días (26 de agosto). En ciudades como Barranquilla, Bogotá y Neiva el pico se alcanzaría aproximadamente a finales del mes de agosto. Por ejemplo, en Bogotá llegaría en 142 días, en Barranquilla en 134 y en Neiva en 100 días. El pico habría llegado más rápido en ciudades como Cartagena (6,3 días) y Cali (56 días) después del 27 de mayo.

Por su parte, el número promedio de nuevos contagios en el pico para Bogotá serían de 22.026, con un intervalo máximo de 59.874 nuevos casos diarios y un mínimo de $8.103 .{ }^{11}$ Sin embargo, el número de casos acumulados (calculados como la sumatoria desde el 20 de abril, tal como se explica en el apéndice) serían 71.080 por millón de habitantes, en una ventana de estimación de 60 días. El número promedio de contagios en el máximo en Barranquilla sería de 9.701, con un intervalo máximo de 40.134 y un mínimo de 1.130 contagios. El acumulado de contagios desde el 27 de mayo hasta el máximo en Barranquilla sería de 82.284 contagios. Para ciudades como Leticia, Cartagena y Villavicencio, que han presentado tasas de crecimiento altas, el número promedio de contagios en el pico sería de 1.808, 544 y 1.261, respectivamente, números que se encuentran dentro de los intervalos de confianza construidos al $95 \%$. Sin embargo, en el acumulado, desde el 27 de mayo el número máximo de contagios para estas mismas ciudades serían $3.866,5.038$ y 3.564 contagios por millón de habitantes, respectivamente.

La tabla 5 presenta la estimación del pico y el número máximo de fallecimientos a partir de la estimación recursiva de la ecuación cuadrática para cada una las unidades de sección cruzada mediante el método de rolling window. De igual forma, presenta el punto de inflexión (tmax) que se alcanza cuando el parámetro estimado que acompaña al término cuadrático resulta ser negativo, así como sus correspondientes intervalos de confianza al $95 \%$.

A nivel nacional, el pico de la curva de fallecimientos se alcanzaría aproximadamente en 95 días (10 de septiembre) cuando la ventana de estimación comienza el 8 de junio, con un valor máximo de 99 días (14 de septiembre). En ciudades como Bogotá sorprende que el pico llegaría solo

10 Este resultado coincide con pronósticos que utilizan modelos epidemiológicos más elaborados, como los del profesor Diego Rosselli, quien encuentra que el pico se alcanzaría el 28 de agosto, con más de 10 mil casos diarios. Este pico se mantendría más o menos hasta el 22 de octubre. De ahí en adelante, los contagios se reducen de manera gradual.

11 Dado que los valores se encuentran en logaritmos, los niveles de contagios se calculan tomando el exponencial de ese número promedio. 
TIEMPO \& ECONOMÍA

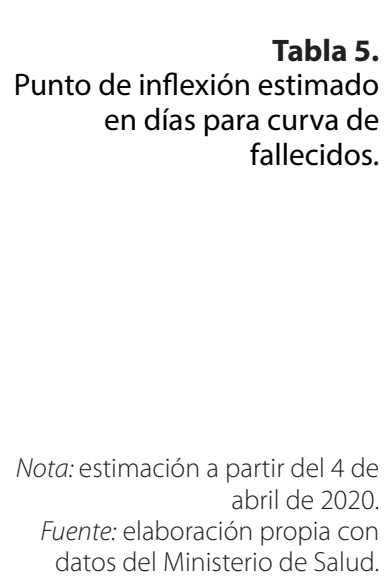

datos del Ministerio de Salud.

\begin{tabular}{|c|c|c|c|c|c|c|c|c|c|c|}
\hline Variables & Barranquilla & Bogotá & Cali & C/gena & Colombia & Leticia & Medellín & Neiva & V/vicencio \\
\hline Tmaxf & 73.13 & 208.6 & 40.69 & 114.6 & 95.34 & 30 & 40.04 & 28.19 & 44.34 \\
\hline Inferiortf & 68.72 & 204.2 & 36.28 & 110.2 & 90.93 & 25.59 & 35.63 & 23.78 & 39.93 \\
\hline Superiortf & 77.54 & 213 & 45.1 & 119 & 99.75 & 34.41 & 44.45 & 32.6 & 48.75 \\
\hline \multicolumn{7}{|c|}{ Número máximo de fallecidos en el pico estimado* } \\
\hline Variables & Barranquilla & Bogotá & Cali & C/gena & Colombia & Leticia & Medellín & Neiva & V/vicencio \\
\hline Zmaxf & 2.228 & 6.723 & 3.88 & 4.556 & 6.99 & 4.995 & 0.679 & 1.587 & 2.736 \\
\hline Inferiorzf & 0.823 & 5.318 & 2.475 & 3.151 & 5.585 & 3.589 & 0.726 & 0.182 & 1.33 \\
\hline Superiorzf & 3.633 & 8.128 & 5.285 & 5.962 & 8.395 & 6.4 & 2.085 & 2.993 & 4.141 \\
\hline
\end{tabular}

hasta octubre, lo cual se podría explicar si se presenta una segunda ola o rebrote de la epidemia, como lo han estimado Cordovez et al. (2020). El pico de fallecidos habría llegado más rápido en ciudades como Neiva (28 días) y Leticia (30 días) en el mes de mayo. El número promedio de fallecidos en el pico en Bogotá sería del orden de 8.124 personas, con un intervalo máximo de 33.610 y un mínimo de 2.003 contagios. El número promedio de fallecidos durante el pico en Medellín sería de 2.085. A nivel nacional, el promedio de fallecidos en el pico sería del orden de 10.966, con un intervalo máximo de 44.471 y un mínimo de 2.704 individuos.

La estimación de las ecuaciones de contagios y fallecidos por medio de la técnica de rolling window permite predecir el comportamiento de estas dos variables a través del tiempo y determinar si el pico habría llegado antes de lo previsto. En las figuras 9 y 10 se presenta la evolución de la variación absoluta de los contagios y fallecimientos. A nivel nacional, un primer pico habría llegado, al parecer, el pasado 6 de mayo y un segundo pico el 9 de junio. A partir de este momento, la predicción de la variación absoluta del número de casos activos (descontando fallecidos y recuperados) comienza a descender gradualmente, y de acuerdo con la estimación del momento en donde no existiría ningún caso de contagio (to), estos se darían 60 días después de alcanzarse el pico, es decir, en el mes de octubre, tal como se aprecia en la tabla 6.

El mismo comportamiento exhiben ciudades como Bogotá y Barranquilla, donde al parecer el pico se habría alcanzado el pasado 9 de junio y 26 de mayo, respectivamente. De acuerdo con las estimaciones de la tabla 8 , el momento estimado (to) donde ya no existirán contagios y fallecimientos después del pico de la pandemia en Barranquilla y Bogotá sería el 10 de septiembre y el 2 de noviembre, respectivamente. 


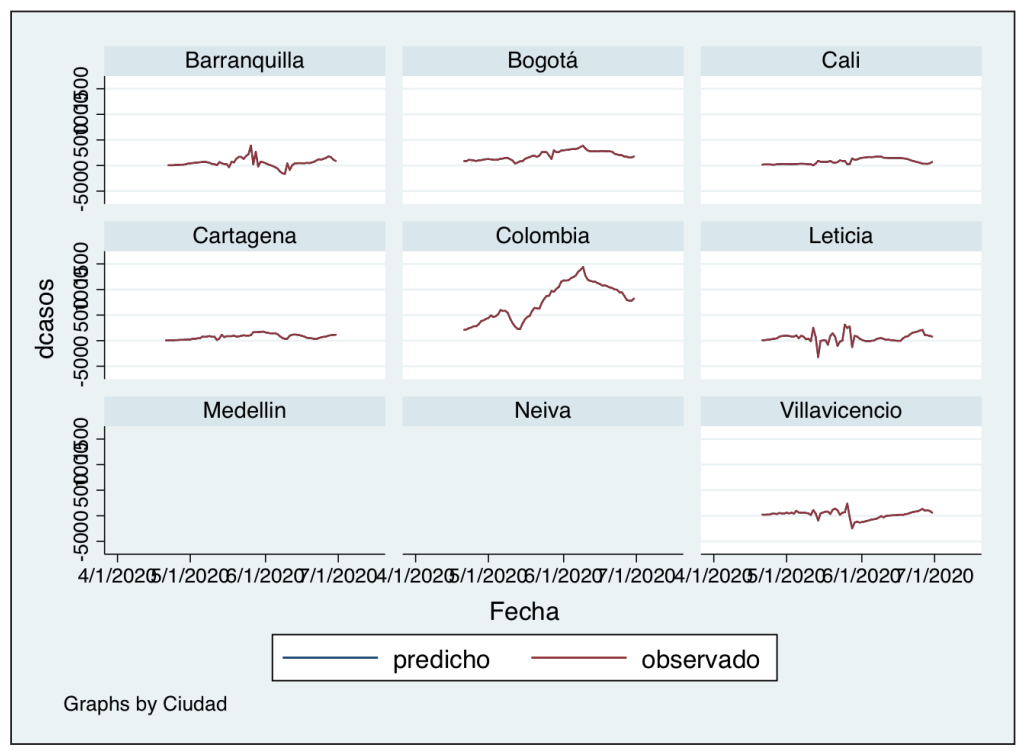

\begin{tabular}{|c|c|c|c|c|c|c|c|c|c|}
\hline Variables & Barranquilla & Bogotá & Cali & C/gena & Colombia & Leticia & Medellín & Neiva & V/vicencio \\
\hline To & 10.37 & 63.43 & 32.63 & 13.07 & 69.9 & 54.41 & 51.49 & 18.31 & 8.211 \\
\hline Lower & 8.89 & 61.95 & 31.15 & 11.59 & 68.42 & 52.93 & 50.01 & 16.83 & 6.74 \\
\hline Upper & 11.85 & 64.91 & 34.11 & 14.55 & 71.38 & 55.89 & 52.97 & 19.79 & 9.69 \\
\hline \multicolumn{7}{|c|}{ Estimación del momento en donde no existirán fallecidos } \\
\hline Variables & Barranquilla & Bogotá & Cali & C/gena & Colombia & Leticia & Medellín & Neiva & V/vicencio \\
\hline To & 52.56 & 0.642 & 8.576 & 35.9 & 2.973 & 62.87 & 294.9 & 14.5 & 13.76 \\
\hline Lower & 50.07 & -1.85 & 6.09 & 33.41 & 0.48 & 60.38 & 292.41 & 12.01 & 11.27 \\
\hline Upper & 55.05 & 3.13 & 11.07 & 38.39 & 5.46 & 65.36 & 297.39 & 16.99 & 16.25 \\
\hline
\end{tabular}

Por su parte, la figura 9 presenta la predicción realizada a partir de la estimación de la ecuación de fallecidos de manera recursiva mediante rolling window. Llama la atención el caso de Leticia, en donde el gráfico exhibe la presencia de dos picos: el primero el 9 de junio y el segundo el 21. Después del segundo pico en Leticia, el momento estimado en donde no existirían fallecidos se presentaría el 28 de julio (62 días después del pico).

A nivel nacional se observan varios picos, de los cuales el más alto se presenta el 21 de junio. A partir de esa fecha se presenta una reducción sostenida en el número de fallecidos, lo cual también ocurre en la ciudad de Bogotá. Por su parte, en Barranquilla, al parecer, el pico más alto de fallecidos se pudo haber presentado el 28 de mayo. Después de esa fecha el número de fallecidos se reduce de manera sostenida hasta el 18 de julio, cuando se estimaría que no existirá ningún fallecido (tabla 8).
Figura 9.

Predicción de nuevos contagios (rolling window)

Nota: estimación a partir del 4 de abril de 2020.

Fuente: elaboración propia con datos del Ministerio de Salud.

\section{Tabla 6.}

Estimación del momento en que no existirán contagios (días después del pico)

Fuente: elaboración propia con datos del Ministerio de Salud. 
TIEMPO \& ECONOMÍA Vol. 8 N. ${ }^{\circ} 1$ | Enero - Junio del 2021 pp. $123-160$

Figura 10.

Predicción de nuevos fallecidos (rolling window)

Fuente: elaboración propia con datos del Ministerio de Salud.

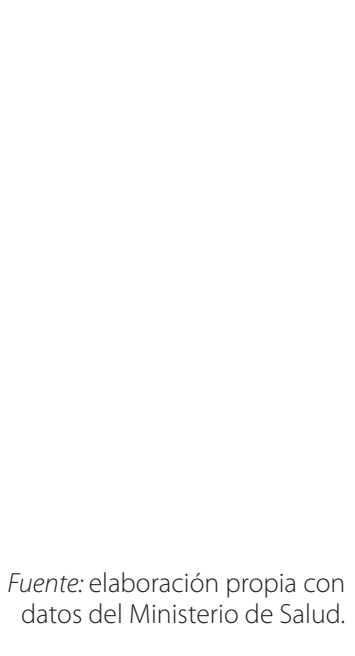

\section{IMPACTO DE LAS MEDIDAS DE CONFINAMIENTO}

En este apartado se estima el posible impacto de las medidas de confinamiento adoptadas por el Gobierno Nacional con el fin de responder a la expansión de la pandemia, tales como el establecimiento de la cuarentena, diferentes formas de distanciamiento inteligente y la apertura gradual de sectores. Para validar si estas medidas lograron reducir el número de contagios y fallecidos se estima la ecuación 7, la cual incorpora variables binarias que capturan el momento en donde se implementan las medidas. Además, se incluye un índice de respuesta del gobierno a la pandemia calculado por la Universidad de Oxford, el cual se construye a partir de 17 indicadores, tales como el cierre de colegios y las restricciones de viajes en cualquier medio de transporte. Se trata de un índice compuesto que toma valores entre 0 y 100 , donde los valores cercanos a 100 indican una estricta respuesta por parte del gobierno a la pandemia (Petherick et al., 2020).

Es importante resaltar que el ejercicio que se muestra en esta sección es preliminar y no se concentra en el impacto de la pandemia sobre indicadores socioeconómicos relevantes, lo cual se podría implementar para una agenda futura de investigación, en la que el autor viene trabajando. Por lo tanto, el objetivo del ejercicio es medir el impacto de las medidas de aislamiento y restricción adoptadas por el gobierno sobre variables de resultado como el número de contagios y fallecidos. 
El modelo dinámico de diferencias en diferencias que se pretende estimar en esta sección sigue la metodología sugerida por Cerulli (2019), la cual utiliza el comando TVDIF de STATA con el fin de estimar los efectos promedio del tratamiento (ATE, por sus siglas en inglés) de las medidas de restricción implementadas por el gobierno, incluyendo variables binarias de tratamiento que cambian en el tiempo. La ecuación a estimar para el número de contagios y fallecidos presenta la siguiente forma:

$$
\ln y_{i t}=\mu_{i t}+\beta_{-1} D_{i t-1}+\beta_{0} D_{i t}+\beta_{+1} D_{i t+1}+\gamma \boldsymbol{X}_{i t}+\theta_{i}+\varepsilon_{i t} \quad \text { (Ec. 9) }
$$

Donde el coeficiente $\beta+1$ mide el impacto del tratamiento un período después de que este haya sucedido, $\beta-1$ mide el impacto del tratamiento un período antes de que el tratamiento haya ocurrido y $\theta_{i}$ recoge el efecto fijo de grupo.

Se supone que el tratamiento $D_{i t}$ sucede una sola vez a lo largo del período de análisis y, por ende, existirá una secuencia de tratamientos posibles a lo largo del tiempo. El parámetro de interés a estimar es el ATE, ${ }^{12}$ el cual está definido para dos resultados potenciales $w^{j}$ y $w^{k}$ como:

$$
A T E_{j k}=E\left[\ln y_{i t}\left(w^{j}\right)-\ln y_{i t}\left(w^{k}\right)\right], \forall(i, t) . \quad \text { (Ec. 10) }
$$

Los resultados de la estimación para las ecuaciones que toman como variables de resultado contagios y fallecidos se presentan en la tabla 7 . El indicador de tratamiento en la ecuación de contagios (did) es una variable binaria que se construyó como la interacción entre la variable dummy de cuarentena y la variable dummy del grupo de tratados. Es decir, la variable dummy de cuarentena se construyó asignando el valor de 1 después del 26 de marzo (inicio de la cuarentena) y cero en caso contrario. Por su parte, la variable binaria de tratados toma el valor de 1 para las ciudades que presentaban el mayor crecimiento de contagios y fallecimientos (Bogotá, Cali, Cartagena y Colombia) y cero en caso contrario. De esta forma, la variable did sería el estimador de diferencias en diferencias dinámico, que recogería el impacto de las medidas de confinamiento o las restricciones impuestas por el Gobierno Nacional para mitigar la pandemia.

12 En términos de la ecuación equivale a estimar los parámetros, $\beta_{-1}, \beta_{+1}$ y $\beta_{0}$ verificar si son estadísticamente significativos y diferentes a cero. 
TIEMPO \& ECONOMÍA

Vol. 8 N. ${ }^{\circ} 1$ | Enero - Junio del 2021

pp. $123-160$

Tabla 7.

Estimación del impacto de las medidas de confinamiento sobre los contagios

\begin{tabular}{|c|c|c|c|c|c|}
\hline \multicolumn{2}{|c|}{ Variable dependiente: contagios } & \multirow[b]{2}{*}{ Efecto Fijo } & \multicolumn{3}{|c|}{ Variable dependiente: fallecidos } \\
\hline Variables & MCO & & Variables & MCO & Efecto Fijo \\
\hline \multirow[t]{2}{*}{ D_F4 } & $2.311^{* * *}$ & 0.0360 & D_F7 & -0.159 & $0.0950^{*}$ \\
\hline & $(0.657)$ & $(0.124)$ & & $(0.833)$ & $(0.0469)$ \\
\hline \multirow[t]{2}{*}{ _D_F3 } & -0.00227 & $-0.0374^{*}$ & D_F6 & -0.0904 & $0.0543^{*}$ \\
\hline & $(0.882)$ & $(0.0168)$ & & $(0.834)$ & $(0.0281)$ \\
\hline \multirow[t]{2}{*}{ D_F2 } & -0.0256 & $-0.0640^{* * *}$ & D_F2 & 0.0764 & -0.0133 \\
\hline & $(0.887)$ & $(0.0186)$ & & $(0.858)$ & $(0.0348)$ \\
\hline \multirow[t]{2}{*}{ _D_F1 } & -0.0182 & $-0.0496^{* * *}$ & _D_F1 & 0.0292 & -0.0175 \\
\hline & $(0.890)$ & $(0.0147)$ & & $(0.857)$ & $(0.0150)$ \\
\hline \multirow[t]{2}{*}{ Did } & -0.0226 & $-0.0774^{* *}$ & dummy40 & 0.180 & $-0.0396^{* *}$ \\
\hline & (0.898) & $(0.0332)$ & & $(0.862)$ & $(0.0134)$ \\
\hline \multirow[t]{2}{*}{-D_L1 } & -0.0173 & $-0.0420^{* * *}$ & _D_L3 & 0.0755 & 0.0233 \\
\hline & $(0.897)$ & $(0.0120)$ & & $(0.749)$ & $(0.0437)$ \\
\hline \multirow[t]{2}{*}{ D_L2 } & -0.0171 & $-0.0439^{* * *}$ & _D_L4 & 0.123 & 0.0626 \\
\hline & $(0.901)$ & $(0.0131)$ & & $(0.727)$ & $(0.0513)$ \\
\hline \multirow[t]{2}{*}{ _D_L3 } & -0.00637 & $-0.0372^{* *}$ & _D_L5 & 0.0860 & 0.00643 \\
\hline & $(0.900)$ & $(0.0152)$ & & $(0.712)$ & $(0.0312)$ \\
\hline \multirow[t]{2}{*}{ _D_L4 } & -0.177 & -0.618 & _D_L6 & 0.0147 & 0.00817 \\
\hline & $(0.652)$ & $(0.389)$ & & $(0.706)$ & $(0.0116)$ \\
\hline \multirow[t]{2}{*}{ Closcoll } & 0.241 & -0.264 & _D_L7 & 0.0630 & 0.0674 \\
\hline & $(0.384)$ & $(0.190)$ & & $(0.698)$ & $(0.0513)$ \\
\hline \multirow[t]{2}{*}{ L.closcoll } & -0.0819 & 0.132 & D_L8 & -0.214 & 0.0241 \\
\hline & $(0.384)$ & $(0.117)$ & & $(0.693)$ & $(0.0368)$ \\
\hline \multirow[t]{2}{*}{$t$} & $0.0598^{* *}$ & $0.106^{* * *}$ & _D_L9 & 0.0892 & 0.0245 \\
\hline & $(0.0238)$ & $(0.0200)$ & & $(0.693)$ & $(0.0183)$ \\
\hline \multirow[t]{2}{*}{$\mathrm{t} 2$} & -0.000215 & $-0.000651^{* * *}$ & _D_L10 & 0.0715 & -0.0122 \\
\hline & $(0.000303)$ & $(0.000182)$ & & $(0.530)$ & $(0.0326)$ \\
\hline \multirow[t]{2}{*}{ R } & 0.124 & 0.610 & R & -2.749 & $1.533^{*}$ \\
\hline & (1.565) & $(0.457)$ & & $(2.550)$ & $(0.775)$ \\
\hline \multirow[t]{2}{*}{ IRG } & -0.0157 & $0.0501^{*}$ & $\mathrm{t}$ & -0.0253 & $0.0373^{* *}$ \\
\hline & $(0.0725)$ & $(0.0227)$ & & $(0.0465)$ & $(0.0126)$ \\
\hline \multirow[t]{2}{*}{ L.IRG } & $0.116^{*}$ & -0.00450 & $\mathrm{t} 2$ & 0.000605 & $-0.000298^{* *}$ \\
\hline & $(0.0681)$ & $(0.0146)$ & & $(0.000583)$ & $(0.000122)$ \\
\hline \multirow[t]{2}{*}{ Constante } & -5.099 & -0.762 & Constante & $7.108^{*}$ & 0.150 \\
\hline & (4.896) & $(2.291)$ & & $(4.039)$ & (1.497) \\
\hline $\mathrm{N}$ & 941 & 941 & $\mathrm{~N}$ & 952 & 952 \\
\hline R-cuadrado & 0.628 & 0.876 & R-cuadrado & 0.061 & 0.545 \\
\hline Grupos & & 9 & Groups & & 9 \\
\hline Ciudad EF & & Si & Ciudad EF & & $\mathrm{Si}$ \\
\hline
\end{tabular}

$p<0.01, * * p<0.05, * p<0.1$ Fuente: elaboración propia con datos del Ministerio de Salud. 
Los resultados reportados en la tabla 7 muestran que la estimación de la cuarentena generó una caída en el número de contagios de aproximadamente $7 \%$, ceteris paribus, el cual resultó ser estadísticamente significativo y diferente de cero en el caso de la estimación por efecto fijo, pero no para la estimación por MCO. El efecto de tratamiento sobre los contagios tiene una influencia dinámica importante a través del tiempo una vez es implementado. En efecto, el período previo al tratamiento se vio afectado de manera importante por el tratamiento actual, lo cual se puede percibir en que los parámetros estimados que acompañan a las variables binarias_D_F1,_D_F2 y_D_F3 resultaron ser estadísticamente significativas y con signo negativo, mostrando que la cuarentena generó una caída en la tasa de contagios diaria de aproximadamente $5 \%$. Los efectos de la cuarentena en los períodos siguientes al momento de su implementación $(t+1)$ fueron igualmente importantes, puesto que los parámetros estimados que acompañan a las variables binarias_D_L1,_D_L2 y_D_L3 presentaron el signo negativo, lo que implicó una caída acumulada en el número de contagios después del impacto de $12,3 \%$. Esto supuso que el período post tratamiento impactara de manera importante la tasa de contagios una vez dictada la medida de confinamiento por parte del gobierno.

De igual forma, se incluyeron otras medidas adoptadas por el gobierno, como el cierre de colegios (closcoll), y un indicador de respuesta del gobierno frente a la pandemia (IRG) calculado por la Universidad de Oxford. ${ }^{13}$ En el caso del cierre de colegios, el parámetro estimado presentó el signo negativo, es decir, la medida generó una reducción en el número de contagios; sin embargo, esta medida no es estadísticamente significativa. Por su parte, la respuesta del gobierno frente a la pandemia no fue eficaz para reducir el número de contagios, tanto en la estimación por efecto fijo como en la estimación por MCO.

De otro lado, la estimación del impacto del confinamiento sobre la variable de resultado de fallecidos no es concluyente. La variable de tratamiento en esta ecuación fue la variable de cuarentena que toma el valor de 1 una vez implementada ( 26 de marzo) y ceros en caso contrario. Esta solamente resultó ser estadísticamente significativa de manera contemporánea y presentó el signo esperado (negativo) en la ecuación estimada por

13 El índice de respuesta de los gobiernos a la pandemia (IRG), calculado por la universidad de Oxford, muestra que Colombia respondió rápidamente a la emergencia a través del establecimiento de medidas de confinamiento, las cuales continúan siendo de las más estrictas hasta el momento, en comparación con otros países. 
efecto fijo, lo que implicó que, en promedio, la medida generó una caída en el número de muertes de 3,9\%, aunque su impacto no fue significativo temporalmente. El impacto de la respuesta de gobierno medida a través del índice IRG genera un efecto en el número de muertes de manera rezagada, aunque su magnitud es muy pequeña, pues la reducción aproximada en el número de muertes por COVID-19 fue apenas 0,012 \%. El hecho de que el impacto de las medidas de confinamiento en la ecuación de fallecidos no resultó ser significativo podría implicar que muchos fallecidos tenían antecedentes relacionados con enfermedades de base y que algunas personas se recuperaron de manera satisfactoria, lo cual debería estudiarse en una agenda de investigación futura a partir de otros modelos que capturen estos factores.

El virus todavía se está expandiendo y la tendencia creciente cada vez es más preocupante, a pesar del endurecimiento de las medidas de confinamiento, las cuales parecen menos efectivas. La realización de pruebas para detectar el virus no está creciendo tan rápido como su propagación, el rastreo de contactos parece no estar funcionando y el número de camas disponibles en las UCl está alcanzando los máximos niveles de ocupación. Dado este contexto, los gobiernos locales han introducido medidas más estrictas de confinamiento, cuya ejecución ha sido difícil debido, en parte, a la escasez de recursos y a la fatiga en que se encuentran las personas en diferentes regiones, lo que se constituye en un desafío no solo para el gobierno central sino también para los gobiernos locales, quienes enfrentan condiciones económicas cada vez más precarias.

A pesar de que las medidas tempranas adoptadas por Colombia lograron aplazar el pico de contagios y disminuir la propagación del virus, la tendencia reciente de la enfermedad continúa creciendo de manera exponencial, por lo que se requiere de un trabajo conjunto entre las autoridades de salud y económicas a fin de mitigar los efectos devastadores de la pandemia.

Algunas opciones que las autoridades podrían implementar con el fin de hacer frente a la catástrofe generada por la pandemia podrían ser las siguientes:

- Fortalecer la infraestructura de salud. Lo que significa contar con un volumen de profesionales con todo el equipo necesario para su protección y al mismo tiempo incrementar el número de $\mathrm{UCl}$ en todo el país. 
- Promover el distanciamiento social y el autocuidado. Esto resulta muy importante dados los altos porcentajes de máxima capacidad en las $\mathrm{UCl}$, lo que involucra promover campañas para que las personas no frecuentan espacios cerrados de alta movilidad.

- Incrementar la aplicación de pruebas para detectar el virus y rastrear más el número de contactos. A pesar de los esfuerzos del gobierno por aumentar el número de pruebas, se requiere un mayor trabajo para reducir el rezago que existe entre los síntomas de la enfermedad y su diagnóstico, al tiempo que se fortalece la trazabilidad de los contagios y se reduce las tasas de positividad.

- Establecimiento de políticas diferenciales a nivel de regiones. Muchos de los municipios de Colombia están libre de COVID-19, por lo tanto, las políticas de contención de la enfermedad se podrían implementar de manera más flexible y de acuerdo con las necesidades de cada región.

- Aumentar la cobertura de los programas de apoyo económico, principalmente a los hogares más pobres y vulnerables, que carecen de redes de seguridad social que ayudarían a paliar los efectos nocivos de la pandemia, tal como lo ha venido haciendo el programa Ingreso Solidario.

\section{COMENTARIOS FINALES}

Los modelos con tendencia cuadrática estimados para el número de contagios y fallecimientos presentan un muy buen ajuste y describen de manera adecuada la dinámica del nuevo coro navirus a través del tiempo en Colombia. La trayectoria futura del COVID-19 no solo depende de su tasa de crecimiento exponencial a través del tiempo, sino también de la evolución del número de reproducción efectiva, que para el caso de Colombia sigue siendo mayor a uno y se ubica en el tramo ascendente de las curvas de contagios y fallecidos.

Los resultados de esta investigación promueven la realización de trabajos futuros que pretendan analizar la manera en que choques exógenos, como la aparición de una pandemia, afectan a la economía, así como cuantificar los impactos nocivos sobre esta desde diferentes metodologías. Un canal importante para analizar sería el deterioro del mercado laboral, manifestado en grandes pérdidas de empleo, como las que se registraron en los meses de abril y mayo, con tasas de desempleo de 19,8 y $21,4 \%$, respectivamente. El 
número de personas que perdieron su empleo fue del orden de 5,5 millones en abril y de 4,9 millones en mayo, con respecto a iguales meses del año anterior. Adicionalmente, los efectos perversos del COVID-19 sobre el mercado laboral tienen fuertes consecuencias dependiendo del género, pues el impacto negativo ha sido más severo para las mujeres que para los hombres. Al respecto, de acuerdo con el DANE, el número de mujeres empleadas se redujo en $22,1 \%$ en mayo, con respecto a igual mes del año anterior, comparado con una caída de $14,9 \%$ para los hombres.

Otro aspecto interesante por destacar a partir de los resultados de este documento tiene que ver con las pérdidas futuras de capital humano debido a la interrupción en los procesos de formación a nivel de educación superior, dentro de las que sobresalen la pérdida de ingresos de los hogares más vulnerables con empleos informales, que fueron fuertemente golpeados por la pandemia. Es posible que la interrupción de un semestre de formación en la universidad implique menos oportunidades de enganche en el mercado laboral y la posibilidad de obtener tasas de retorno a la educación adecuadas a la inversión necesaria en el proceso de formación.

El efecto de la respuesta del gobierno a la pandemia sobre los contagios tiene un efecto dinámico importante a través del tiempo una vez implementado, ya que el período previo al tratamiento se vio afectado de manera importante por el tratamiento actual. Los efectos de la cuarentena en los períodos siguientes al momento de su implementación $(t+1)$ fueron igualmente importantes, lo que implicó una caída acumulada en el número de contagios después del impacto de $12,3 \%$. Se concluye que el período postratamiento impactó de manera importante a los contagios una vez dictada la medida de confinamiento, cuyo impacto sobre la variable resultado de fallecidos fue débil. Lo anterior implica que muchos fallecidos tenían antecedentes relacionadas con enfermedades de base y que algunas personas afectadas se recuperaron de manera satisfactoria, lo cual debería estudiarse a partir de otros modelos que capturen estos factores, los que quedan por fuera de este trabajo.

Como muchos otros países, Colombia logró responder a la pandemia producida por el COVID-19 a través del incremento en la realización de pruebas, el establecimiento de estrictas medidas de confinamiento, trazabilidad de los contactos e incrementos en la capacidad de UCI. Al parecer, la estrategia seguida por Colombia en torno a las medidas de confinamiento se tomó de forma muy temprana, si se tiene en cuenta la severidad de la pandemia 
en comparación con otros países, la cual continúa siendo una de las medidas más estrictas. No obstante, en la actualidad, debido a las tendencias recientes en la propagación del virus existen algunas señales con el manejo de la pandemia, toda vez que la tasa de positividad de la enfermedad se ha ubicado por encima del $10 \%$. A pesar de que no existe una respuesta clara frente a cuántas pruebas se deben realizar, la Organización Mundial de la Salud sugiere que los países deben realizar pruebas con el fin de mantener las tasas de positividad por debajo del $10 \%$.

Como agenda futura de investigación, resulta interesante medir el impacto de las medidas económicas tomadas por el gobierno con el fin de contener los efectos nocivos de la pandemia, así como algunas señales de recuperación que podría presentar la economía colombiana en los próximos años. Igualmente, resulta llamativo medir los costos sociales, por ejemplo, en pobreza y desigualdad, los cuales podrían manifestar un enorme retroceso en cuanto a las metas logradas durante los últimos quince años, lo que indudablemente afectará el desarrollo económico del país a largo plazo.

\section{REFERENCIAS}

Acemoglu, D., Chernozhukov, V., Werning, I., \& Whinston, M. D. (2020). A multi-risk SIR model with optimally targeted lockdown. Massachusetts Institute of Technology. https://economics.mit.edu/files/19698

Alvarez, F. E., Argente, D., \& Lippi, F. (2020). A simple planning problem for COVID-19 lockdown (NBER Working Paper n. 26981). National Bureau of Economic Research. https://www.nber.org/papers/w26981

Álvarez, A., León, D., Medellín, M., Zambrano, A., \& Zuleta, H. (2020). El coronavirus en Colombia: Vulnerabilidad y opciones de política (PNUD LAC C19 PDS n. ${ }^{\circ}$ 11.). Programa de las Naciones Unidas para el Desarrollo.

Arroyo-Marioli, F., Bullano, F., Kucinskas, S., \& Rondón-Moreno, C. (2020). Tracking R of COVID-19: A new real-time estimation using the Kalman filter. SSRN, May. http://dx.doi.org/10.2139/ssrn.3581633

Aum, S., Lee, S. Y., \& Shin, Y. (2020). Inequality of fear and self-quarantine: Is there a trade-off between GDP and public health? (NBER Working Paper n. ${ }^{\circ}$ 27100). National Bureau of Economic Research. https://www.nber. org/papers/w27100

Avery, C., Bossert, W., Clark, A., Ellison, G. \& Fisher-Ellison, S. (2020). Policy implications of models of the spread of coronavirus: Perspectives and 
opportunities for economists (NBER Working Paper $n .{ }^{\circ}$ 27007). National Bureau of Economic Research. https://www.nber.org/papers/w27007 Bardey, D., Fernandez, M., \& Gravel, A. (2020). COVID-19: Some Data Analysis. https://sites.google.com/view/covid19somedataanalysis/home

Berger, D. W., Herkenhoff, K. F., \& Mongey, S. (2020). An SEIR infectious disease model with testing and conditional quarantine (NBER Working Paper n. ${ }^{\circ}$ 26901). National Bureau of Economic Research. https://www.nber. org/papers/w26901 https://doi.org/10.21034/sr.597

Bethune, Z. A., \& Korinek, A. (2020). COVID-19 Infection Externalities: Trading Off Lives vs. Livelihoods (NBER Working Paper n. ${ }^{\circ} 27009$ ). National Bureau of Economic Research. https://www.nber.org/papers/w27009 https://doi.org/10.3386/w27009

Bodenstein, M., Corsetti, G., \& Guerrieri, L. (2020). Social distancing and supply disruptions in a pandemic (Finance and Economics Discussion Series 2020-031). Board of Governors of the Federal Reserve System. https:// www.federalreserve.gov/econres/feds/social-distancing-and-supply-disruptions-in-a-pandemic.htm https://doi.org/10.3386/w27009

Bonet-Morón, J. A., Ricciulli-Marín, D., Pérez-Valbuena, G. J., Galvis-Aponte, L. A., Haddad, E. A., Araújo-Junior, I., \& Perobelli, F. (2020). Impacto económico regional del COVID-19 en Colombia: Un análisis insumo-producto (Documentos de trabajo sobre Economía Regional y Urbana n. ${ }^{\circ}$ 288). Banco de la República. https://www.banrep.gov.co/es/impacto-economico-regional-del-covid-19-colombia-analisis-insumo-producto https://doi.org/10.32468/dtseru.288

Cerulli, G. (2019). Estimation of pre- and post-treatment average treatment effects with binary time-varying treatment using STATA. The STATA Journal, 19(3), 551-565. https://doi.org/10.1177/1536867X19874224

Chang, R., \& Velasco, A. (2020). Economic policy incentives to preserve lives and livelihoods (NBER Working Paper n. ${ }^{\circ}$ 27099). National Bureau of Economic Research. https://www.nber.org/papers/w27020 https://doi. org/10.3386/w27020

Chari, V. V., Kirpalani, R., \& Phelan, C. (2020). The hammer and the scalpel: On the economics of indiscriminate versus targeted isolation policies during pandemics (NBER Working Paper 27232). National Bureau of Economic Research. https://www.nber.org/papers/w27232 https://doi. org/10.3386/w27232 
Cordovez, J. M., Santos, M., Bravo, C., \& Cascante, J. (2020). Modelación COVID-19, junio 1 de 2020. Universidad de los Andes.

Eichenbaum, M. S., Rebelo, S., \& Trabandt, M. (2020). The macroeconomics of epidemics (NBER Working Paper n. 26882). National Bureau of Economic Research. https://www.nber.org/papers/w26882 https://doi. org/10.3386/w26882

Farboodi, M., Jarosch, G., \& Shimer, R. (2020). Internal and external effects of social distancing in a pandemic (NBER Working Paper n. ${ }^{\circ}$ 27059). National Bureau of Economic Research. https://www.nber.org/papers/ w27059 https://doi.org/10.3386/w27059

Fernández-Villaverde, J., \& Jones, C. (2020). Estimating and simulating a SIRD model of covid-19 for many countries, states, and cities (Working Paper n. ${ }^{\circ}$ 27128). National Bureau of Economic Research. https://www.nber. org/papers/w27128 https://doi.org/10.3386/w27128

Garriga, C., Manuelli, R., \& Sanghi, S. (2020). Optimal management of an epidemic: An application to COVID-19. A Progress Report. Federal Reserve Bank of St. Louis.

Gregory, V., Menzio, G., \& Wiczer, D. G. (2020). Pandemic recession: L or $V$-shaped?. (NBER Working Paper n. 27105). National Bureau of Economic Research. https://www.nber.org/papers/w27105 https://doi. org/10.21034/wp.766

Hornstein, A. (2020). Social distancing, quarantine, contact tracing, and testing: Implications of an augmented SEIR-Mode. Federal Reserve Bank of Richmond. https://doi.org/10.21144/wp20-04

Hurwicz, L. (1962). On the structural form of interdependent systems. In E. Nagel, P. Suppes, \& A. Tarski (eds.), Logic, methodology and philosophy of science (pp. 232-239). Elsevier. https://doi.org/10.1016/S0049237X(09)70590-7

Karin, O., Yinon, M. B., Milo, T., Katzir, I., Mayo, A., Korem, Y., Dudovich, B., Yashiv, E., Zehavi, A. J., Davidovich, N., Milo, R., \& Alon. U. (2020). Adaptive cyclic exit strategies from lockdown to suppress COVID-19 and allow economic activity. medRxiv, May. https://doi. org/10.1101/2020.04.04.20053579

Kermack, W., \& McKendrick, A. G. (1927). A contribution to the mathematical theory of epidemics. The Royal Society Publishing. 
Korolev, I. (2020). Identification and estimation of the SEIRD epidemic model for COVID-19. Binghamton University. https://doi.org/10.1016/j.jeconom.2020.07.038

Lin, Z., \& Meissner, C. (2020). Health vs Wealth? Public Health Policies and the Economy During COVID-19. (NBER Working Paper n. ${ }^{\circ}$ 27099). National Bureau of Economic Research. https://www.nber.org/papers/w27099 https://doi.org/10.3386/w27099

Linton, O., \& Li, S. (2020). When will the COVID-19 pandemic peak? (Cambridge Working Papers in Economics n. ${ }^{\circ}$ 2025). University of Cambridge. https://www.ifs.org.uk/uploads/CW1120-When-will-the-Covid-19pandemic-peak.pdf https://doi.org/10.1920/wp.cem.2020.1120

Liu, S., Weill, Pierre-Olivier, Lindsay, D., Lester, B., \& Kargar, M. (2020). Corporate bond liquidity during the COVID-19 crisis (NBER Working Paper n. ${ }^{\circ}$ 27355). National Bureau of Economic Research. https://www.nber. org/papers/w27355

Ludvigson, S., Ma, S., \& Ng, S. (2020). COVID-19 and the macroeconomic effects of costly disasters (NBER Working Paper n. ${ }^{\circ}$ 26987). National Bureau of Economic Research. https://www.nber.org/papers/w26987 https:// doi.org/10.3386/w26987

Petherick, A., Kira, B., Angrist, N., Hale, T., \& Phillips, T. (2020). Variation in Government responses to COVID-19 (BSG Working Paper Series). University of Oxford.

Stock, J. H. (2020). Data gaps and the policy response to the novel coronavirus (NBER Working Paper n. ${ }^{\circ}$ 26902). National Bureau of Economic Research March. https://doi.org/10.3386/w26902

Toda, A. A. (2020). Susceptible-Infected-Recovered (SIR) Dynamics of COVID-19 and Economic Impact. arXiv, 2003.11221. 


\section{ANEXO}

Suponga que $z_{i}(t)=\phi+\beta t+\gamma t^{2}$. El pico de la función ocurre cuando $\gamma<0$ $y$ tiene lugar en el punto $t_{\max }=-\beta / 2 \gamma$ con un valor máximo de $z_{i} t_{\max }=\phi+\beta t_{\text {max }}$ $+\gamma t_{\text {max }}=\phi-\beta^{2} / 4 \gamma$. El valor de $t$ cuando ya no existen casos se alcanzará cuando la raíz más grande $z_{i}(t)=0$, por ejemplo:

$$
t_{0}=\left[-\beta+\sqrt{\beta^{2}-4 \phi \gamma}\right] / 2 \gamma
$$

El número total de casos a partir del período inicial de la estimación está dado por $N_{\max }=\int_{0}^{\text {to }} \exp (z(s)) d s-t_{0}$. La letalidad de la pandemia sería igual a la relación de $N_{\max }$ de muertes y $N_{\max }$ de casos.

Una vez estimados los parámetros por M.C.O $\hat{\theta}=(\widehat{\phi}, \widehat{\beta}, \hat{\gamma})$ se puede estimar:

$$
\begin{gathered}
\hat{t}_{\max }=-\frac{\hat{\beta}}{2 \hat{\gamma}^{\prime}} \hat{z}_{i}\left(\hat{t}_{\max }\right)=\phi-\frac{\hat{\beta}^{2}}{4 \hat{\gamma}}, \\
\hat{t}_{0}=\left[-\hat{\beta}+\sqrt{\hat{\beta}^{2}-4 \hat{\phi} \hat{\gamma}}\right] / 2 \hat{\gamma}
\end{gathered}
$$

Los errores estándar de los parámetros se estiman a partir del método delta, de la siguiente forma:

$$
\begin{gathered}
\operatorname{avar}\left(\hat{t}_{\max }\right)=\left(0,-\frac{1}{2 \gamma}, \frac{\beta}{2 \gamma^{2}}\right) \operatorname{avar}(\hat{\theta})\left(\begin{array}{c}
0 \\
-\frac{1}{2 \gamma} \\
\frac{\beta}{2 \gamma^{2}}
\end{array}\right) \\
\operatorname{avar}\left[\hat{z}\left(\hat{t}_{\max }\right)\right]=\left(1,-\frac{\beta}{2 \gamma}, \frac{\beta^{2}}{4 \gamma^{2}}\right) \operatorname{avar}(\hat{\theta})\left(\begin{array}{c}
1 \\
-\frac{\beta}{2 \gamma} \\
\frac{\beta^{2}}{4 \gamma^{2}}
\end{array}\right)
\end{gathered}
$$

Donde avar ( $(\hat{\theta})$ es la matriz de covarianzas de los parámetros estimados por M.C.O. Luego, se predice el número de casos y de muertes $\left(y_{s}\right)$ con la expresión $y_{s}=\exp \left(\hat{\phi}+\hat{\beta} t+\hat{\gamma} t^{2}\right) \cdot+1$ y se multiplica por el promedio del exponencial de los residuos estimados por M.C.O. con el fin de corregir el sesgo de transformación. Por último, se estima $N_{\max }$ a través de $N_{\max }=$ $\int_{0}^{\hat{t}_{0}} \exp \left(\hat{\phi}+\hat{\beta} s+\hat{\gamma} s^{2}\right) d s-\hat{t}_{0}$, el cual se puede aproximar a través de la sumatoria de $\exp (\hat{z}(t))$ a lo largo del período de extrapolación. 